Research Article

\title{
Free Vibration Analysis of Symmetrically Laminated Folded Plate Structures Using an Element-Free Galerkin Method
}

\author{
L. X. Peng ${ }^{1,2}$ \\ ${ }^{1}$ College of Civil Engineering and Architecture, Guangxi University, Nanning 530004, China \\ ${ }^{2}$ Guangxi Key Laboratory of Disaster Prevention and Engineering Safety, Guangxi University, Nanning 530004, China \\ Correspondence should be addressed to L. X. Peng; penglx@gxu.edu.cn
}

Received 21 July 2014; Revised 14 November 2014; Accepted 14 November 2014

Academic Editor: Kim M. Liew

Copyright @ 2015 L. X. Peng. This is an open access article distributed under the Creative Commons Attribution License, which permits unrestricted use, distribution, and reproduction in any medium, provided the original work is properly cited.

\begin{abstract}
An element-free Galerkin method for the solution of free vibration of symmetrically laminated folded plate structures is introduced. Employing the mature meshfree folded plate model proposed by the author, a folded laminated plate is simulated as a composite structure of symmetric laminates that lie in different planes. Based on the first-order shear deformation theory (FSDT) and the moving least-squares (MLS) approximation, the stiffness and mass matrices of the laminates are derived and supposed to obtain the stiffness and mass matrices of the entire folded laminated plate. The equation governing the free vibration behaviors of the folded laminated plate is thus established. Because of the meshfree characteristics of the proposed method, no mesh is involved to determine the stiffness and mass matrices of the laminates. Therefore, the troublesome remeshing can be avoided completely from the study of such problems as the large deformation of folded laminated plates. The calculation of several numerical examples shows that the solutions given by the proposed method are very close to those given by ANSYS, using shell elements, which proves the validity of the proposed method.
\end{abstract}

\section{Introduction}

Because of high strength/weight ratio, easy forming, and low cost, folded plate structures have been widely used in many engineering branches, such as roofs, corrugated-cores, and cooling towers. They have much higher load carrying capacity compared to flat plates. Before the invention of fiberreinforced material, folded plates were often made of medal or timber. The application of fiber-reinforced material to folded plate structures was a remarkable advance in engineering, which combined the advantages of fiber-reinforced material and folded plate structure directly and made the structure even lighter and stiffer.

The study of isotropic folded plates had a quite long history, and a variety of methods had emerged. In early days, researchers were short of powerful numerical tools and tried to analyze the structures with various approximations. The beam method and the theory that ignores relative joint displacement were introduced [1]. Although the methods were weak in dealing with generalized folded plate problems, they were simple and fulfilled the demand of fast and easy computation in engineering. Therefore, they are still used in some design environments, where accurate analysis is not the first concern. Researchers such as Gaafar [2], Yitzhaki [3], Yitzhaki and Reiss [4], and Whitney et al. [5] were the first to consider the relative joint displacement of the structures in their methods, which led to more precise analysis results. Goldberg and Leve [6] used the two-dimensional theory of elasticity and the two-way slab theory to analyze folded plates. In their method, both the simultaneous bending and the membrane action of a folded plate were taken into account, and the degree of freedom (DOF) of each point along the joint of the folded plate was chosen to be four (three components of translation and one rotation). Niyogi et al. [7] considered this method as the first to give an exact static solution for folded plates. Yitzhaki and Reiss [4] took the moments along the joints of folded plates as unknown and applied the slope deflection method to the analysis of the folded plates. Bar-Yoseph and Hersckovitz [8] proposed an approximated 
method for folded plates based on Vlasov's theory of thinwall beams. Their method considered a folded plate as a monolithic structure composed of longitudinal beams, which can give good results for long folded plates. Bandyopadhyay and Laad [9] compared two classical methods for folded plates and studied the suitability of these methods for the preliminary analysis of folded plate structures. Lai et al. [10] gave an equation of the middle surface of a simply supported cross V-shaped folded plate roof by using the inclined coordinate system and generalized functions, sign function and step function, and carried out a nonlinear analysis for the folded plate.

The development of computation techniques and computers has aroused research interest in numerical methods for folded plates. A number of methods, such as the finite strip methods (Cheung [11], Golley and Grice [12], Eterovic and Godoy [13]), the combined boundary element-transfer matrix method (Ohga et al. [14]), and the finite element methods (FEM) (Liu and Huang [15], Perry et al. [16], Niyogi et al. [7], and Duan and Miyamoto [17]), have been introduced to solve folded plate problems. Among these methods, the FEMs are the most successful. They are very versatile as they can deal with the problems with complicated geometry, boundary conditions, or loadings easily. However, FEM also has disadvantages. Their solution of a problem is based on the meshes that discretize the problem domain, and any dramatic change of the problem domain will lead to remeshing of the domain, which results in programming complexity, diminished accuracy, and long computation time. Regarding the disadvantage, some researchers proposed the element-free, meshfree, or meshless methods [18-22]. As alternatives to FEMs, the meshfree methods construct their approximated solution of a problem completely in terms of a set of ordered or scattered points that discretize the problem domain; that is, their solution relies on the points other than meshes. No element is required. Without the limit of meshes, the meshfree methods are more applicable than the FEMs and avoid the aforementioned difficulties caused by remeshing in the FEMs.

Bui et al. [23], Bui and Nguyen [24], and Somireddy and Rajagopal [25] have introduced the meshfree methods for vibration analysis of laminated plates. However, few studies on folded laminated plates have been found. There are only Niyongi et al. [7] and Lee et al.s [26] work on vibration and the author's work on bending with a meshfree method, which is also the motive for this paper.

The objective of this paper is to introduce an element-free Galerkin method based on the first-order shear deformation theory (FSDT) $[27,28]$ for the free vibration analysis of folded laminated plates. A symmetrical folded laminated plate is regarded as a composite structure composed of symmetric laminates. The analysis process includes (a) deriving the stiffness and mass matrices of the symmetric laminates that make up a folded plate by the element-free Galerkin method; (b) considering the laminates as super elements and superposing their stiffness and mass matrices to obtain the global stiffness and mass matrices of the folded plate. Some numerical examples are used to demonstrate the convergence and accuracy of the proposed method. The calculated results are compared with the results from the finite element analytical software ANSYS. The proposed method may be used as a potential meshfree tool for the analysis of laminated shell structures.

\section{Moving Least-Squares Approximation}

In the moving least-squares approximation (MLS) [18], a function $v(\mathbf{x})$ in a domain $\Omega$ can be approximated by $v^{d}(\mathbf{x})$ in the subdomain $\Omega_{\mathbf{x}}$ and

$$
v^{d}(\mathbf{x})=\sum_{i=1}^{m} q_{i}(\mathbf{x}) b_{i}(\mathbf{x})=\mathbf{q}^{\mathbf{T}}(\mathbf{x}) \mathbf{b}(\mathbf{x}),
$$

where $q_{i}(\mathbf{x})$ are the monomial basis functions, $b_{i}(\mathbf{x})$ are the corresponding coefficients, $d$ is a factor that measures the domain of influence (or the support) of the nodes, and $m$ is the number of basis functions. In this paper, the quadratic basis $\mathbf{q}^{\mathbf{T}}=\left[1, x, y, x^{2}, x y, y^{2}\right](m=6)$ are used for the laminates. The unknown coefficients $b_{i}(\mathbf{x})$ are obtained by the minimization of a weighted discrete $L_{2}$ norm

$$
\Gamma=\sum_{I=1}^{n} \omega\left(\mathbf{x}-\mathbf{x}_{I}\right)\left[\mathbf{q}\left(\mathbf{x}_{I}\right)^{\mathbf{T}} \mathbf{b}(\mathbf{x})-v_{I}\right]^{2},
$$

where $\omega\left(\mathbf{x}-\mathbf{x}_{I}\right)$ or $\omega_{I}(\mathbf{x})$ is the weight function that is associated with node $I, \omega_{I}(\mathbf{x})=0$ outside $\Omega_{\mathbf{x}}, n$ is the number of nodes in $\Omega_{\mathbf{x}}$ that make the weight function $\omega_{I}(\mathbf{x})>0$, and $v_{I}$ are the nodal parameters. The minimization of $\Gamma$ in (2) with respect to $\mathbf{b}(\mathbf{x})$

$$
\frac{\partial \Gamma}{\partial \mathbf{b}(\mathbf{x})}=0
$$

leads to a set of linear equations

$$
\mathbf{B}(\mathbf{x}) \mathbf{b}(\mathbf{x})=\mathbf{A}(\mathbf{x}) \mathbf{v},
$$

where

$$
\begin{gathered}
\mathbf{B}(\mathbf{x})=\sum_{I=1}^{n} \omega\left(\mathbf{x}-\mathbf{x}_{I}\right) \mathbf{q}\left(\mathbf{x}_{I}\right) \mathbf{q}^{\mathbf{T}}\left(\mathbf{x}_{I}\right), \\
\mathbf{A}(\mathbf{x})=\left[\omega\left(\mathbf{x}-\mathbf{x}_{1}\right) \mathbf{q}\left(\mathbf{x}_{1}\right), \ldots, \omega\left(\mathbf{x}-\mathbf{x}_{n}\right) \mathbf{q}\left(\mathbf{x}_{n}\right)\right] .
\end{gathered}
$$

The coefficients $\mathbf{b}(\mathbf{x})$ are then derived from (4):

$$
\mathbf{b}(\mathbf{x})=\mathbf{B}^{-1}(\mathbf{x}) \mathbf{A}(\mathbf{x}) \mathbf{v} \text {. }
$$

By substituting (7) into (1), the approximation $v^{d}(\mathbf{x})$ is expressed in a standard form as

$$
v^{d}(\mathbf{x})=\sum_{I=1}^{n} N_{I}(\mathbf{x}) v_{I},
$$

where the shape function $N_{I}(\mathbf{x})$ is given by

$$
N_{I}(\mathbf{x})=\mathbf{q}^{\mathbf{T}}(\mathbf{x}) \mathbf{B}^{-1}(\mathbf{x}) \mathbf{A}_{I}(\mathbf{x}) .
$$

From (6), we obtain

$$
\mathbf{A}_{I}(\mathbf{x})=\omega\left(\mathbf{x}-\mathbf{x}_{I}\right) \mathbf{q}\left(\mathbf{x}_{I}\right),
$$

and thus (9) can be rewritten as

$$
N_{I}(\mathbf{x})=\mathbf{q}^{\mathbf{T}}(\mathbf{x}) \mathbf{B}^{-1}(\mathbf{x}) \mathbf{q}\left(\mathbf{x}_{I}\right) \omega\left(\mathbf{x}-\mathbf{x}_{I}\right) .
$$




\section{Meshless Model of a Laminate}

The first step in our analysis is to obtain the stiffness and mass matrices of the laminates that make up a folded plate. The meshless model for a laminate in the local coordinate, as shown in Figure 1, is prescribed with a set of nodes. The DOF of every node is $\left(u_{0}, v_{0}, w, \varphi_{x}, \varphi_{y}\right)$, where $u_{0}, v_{0}$, and $w$ are the nodal translations of the laminate in the $x$-direction, $y$-direction, and $z$-direction, respectively. $\varphi_{x}$ and $\varphi_{y}$ are the rotation about the $y$-axis and the $x$-axis, respectively. The laminate is assumed to have $N$ layers, and the thickness of each layer is $z_{i}(i=1, \ldots, N)$. Therefore, the thickness of $k$ th layer is $h_{k}=z_{k+1}-z_{k}$.

3.1. Displacement Approximation. Based on the FSDT and the MLS approximation, the displacements of the laminate can be approximated by

$$
\begin{aligned}
u(x, y, z, t) & =u_{0}(x, y, t)-z \varphi_{x}(x, y, t) \\
& =\sum_{I=1}^{n} H_{I}(x, y) u_{0 I}(t)-z \sum_{I=1}^{n} H_{I}(x, y) \varphi_{x I}(t) \\
v(x, y, z, t) & =v_{0}(x, y, t)-z \varphi_{y}(x, y, t) \\
& =\sum_{I=1}^{n} H_{I}(x, y) v_{0 I}(t)-z \sum_{I=1}^{n} H_{I}(x, y) \varphi_{y I}(t), \\
w(x, y, t)= & \sum_{I=1}^{n} H_{I}(x, y) w_{I}(t)
\end{aligned}
$$

$$
\begin{aligned}
\mathbf{U}=\left\{\begin{array}{l}
u \\
v \\
w
\end{array}\right\} & =\sum_{I=1}^{n}\left[\begin{array}{ccccc}
H_{I}(x, y) & 0 & 0 & -z H_{I}(x, y) & 0 \\
0 & H_{I}(x, y) & 0 & 0 & -z H_{I}(x, y) \\
0 & 0 & H_{I}(x, y) & 0 & 0
\end{array}\right] \\
& \times\left\{\begin{array}{l}
u_{0 I}(t) \\
v_{0 I}(t) \\
w_{I}(t) \\
\varphi_{x I}(t) \\
\varphi_{y I}(t)
\end{array}\right\} .
\end{aligned}
$$

is used as the weight function. Equation (12) can be written in a matrix form as

parameters of the $T$ th node of the laminate $n$ is the number of nodes of the laminate, and $\varphi_{x}$ and $\varphi_{y}$ are independent of $w$. The shape functions $H_{I}(x, y)$ are obtained from (9), and the cubic spline function

$$
\omega(s)= \begin{cases}\frac{2}{3}-4 s^{2}+4 s^{3}, & s \leq \frac{1}{2}, \\ \frac{4}{3}-4 s+4 s^{2}-\frac{4}{3} s^{3}, & \frac{1}{2}<s \leq 1, \\ 0, & s>1\end{cases}
$$

The strains of the laminate are defined as

$$
\begin{gathered}
\boldsymbol{\kappa}=\left\{\begin{array}{c}
\varepsilon_{x} \\
\varepsilon_{y} \\
\gamma_{x y}
\end{array}\right\}=\left[\begin{array}{c}
u_{0, x}-z \varphi_{x, x} \\
v_{0, y}-z \varphi_{y, y} \\
u_{0, y}+v_{0, x}-z\left(\varphi_{x, y}+\varphi_{y, x}\right)
\end{array}\right]=\sum_{I=1}^{n} \mathbf{B}_{I}^{b} \boldsymbol{\delta}_{I}, \\
\gamma=\left\{\begin{array}{l}
\gamma_{x z} \\
\gamma_{y z}
\end{array}\right\}=\left[\begin{array}{l}
w_{, x}-\varphi_{x} \\
w_{, y}-\varphi_{y}
\end{array}\right]=\sum_{I=1}^{n} \mathbf{B}_{I}^{s} \boldsymbol{\delta}_{I},
\end{gathered}
$$

where

$$
\begin{gathered}
\mathbf{B}_{I}^{b}=\left[\begin{array}{ll}
\mathbf{B}_{0 I} & -z \mathbf{B}_{1 I}
\end{array}\right]=\left[\begin{array}{ccccc}
H_{I, x} & 0 & 0 & -z H_{I, x} & 0 \\
0 & H_{I, y} & 0 & 0 & -z H_{I, y} \\
H_{I, y} & H_{I, x} & 0 & -z H_{I, y} & -z H_{I, x}
\end{array}\right], \\
\mathbf{B}_{0 I}=\left[\begin{array}{cc}
H_{I, x} & 0 \\
0 & H_{I, y} \\
H_{I, y} & H_{I, x}
\end{array}\right], \\
\mathbf{B}_{1 I}=\left[\begin{array}{ccc}
0 & H_{I, x} & 0 \\
0 & 0 & H_{I, y} \\
0 & H_{I, y} & H_{I, x}
\end{array}\right],
\end{gathered}
$$




$$
\begin{gathered}
\mathbf{B}_{I}^{s}=\left[\begin{array}{ll}
\mathbf{0} & \mathbf{B}_{2 I}
\end{array}\right]=\left[\begin{array}{ccccc}
0 & 0 & H_{I, x} & -H_{I} & 0 \\
0 & 0 & H_{I, y} & 0 & -H_{I}
\end{array}\right], \\
\mathbf{B}_{2 I}=\left[\begin{array}{ccc}
H_{I, x} & -H_{I} & 0 \\
H_{I, y} & 0 & -H_{I}
\end{array}\right],
\end{gathered}
$$

"x" refers to the derivatives of $x$, and ", $y$ " refers to the derivatives of $y$.

3.2. Governing Equation. In free vibration, the strain energy and kinetic energy of the laminate are, respectively,

$$
\begin{gathered}
\Pi=\frac{1}{2} \iiint_{-h / 2}^{h / 2} \boldsymbol{\kappa}^{\mathrm{T}} \mathbf{D} \boldsymbol{\kappa} \mathrm{d} z \mathrm{~d} x \mathrm{~d} y+\frac{1}{2} \iint \boldsymbol{\gamma}^{\mathrm{T}} \mathbf{A}_{s} \gamma \mathrm{d} x \mathrm{~d} y \\
\mathrm{~T}_{0}=\frac{1}{2} \iiint_{-h / 2}^{h / 2} \dot{\mathrm{U}}^{\mathrm{T}} \rho \dot{\mathrm{U}} \mathrm{d} z \mathrm{~d} x \mathrm{~d} y
\end{gathered}
$$

where

$$
\begin{gathered}
\mathbf{D}=\left[\begin{array}{ccc}
\bar{Q}_{11}^{(k)} & \bar{Q}_{12}^{(k)} & \bar{Q}_{16}^{(k)} \\
\bar{Q}_{21}^{(k)} & \bar{Q}_{22}^{(k)} & \bar{Q}_{26}^{(k)} \\
\bar{Q}_{61}^{(k)} & \bar{Q}_{62}^{(k)} & \bar{Q}_{66}^{(k)}
\end{array}\right], \\
\widetilde{\mathbf{A}}_{s}=\left[\begin{array}{cc}
\widetilde{A}_{55} & \widetilde{A}_{45} \\
\widetilde{A}_{45} & \widetilde{A}_{44}
\end{array}\right], \\
\widetilde{A}_{i j}=k_{c} \int_{-h / 2}^{h / 2} \bar{Q}_{i j}^{(k)} \mathrm{d} z=k_{c} \sum_{k=1}^{N} \bar{Q}_{i j}^{(k)}\left(z_{k+1}-z_{k}\right), \\
(i, j=4,5),
\end{gathered}
$$

$\bar{Q}_{i j}(i, j=1,2,6,4,5)$ are the material stiffness that are defined in [28], $k_{c}=5 / 6$ is the shear correction factor, and $h$ is the thickness of the laminate. $\rho$ is the density of the material.

According to Hamilton's principle,

$$
\delta \int_{t_{1}}^{t_{2}}\left(\mathrm{~T}_{0}-\Pi\right) \mathrm{d} t=0
$$

The substitution of (14) to (17) into (19) gives

$$
\mathbf{K} \boldsymbol{\delta}+\mathbf{M} \ddot{\boldsymbol{\delta}}=\mathbf{0},
$$

where

$$
\begin{aligned}
\boldsymbol{\delta} & =\left\{\boldsymbol{\delta}_{1}^{\mathrm{T}} \quad \boldsymbol{\delta}_{2}^{\mathrm{T}} \cdots \boldsymbol{\delta}_{n}^{\mathrm{T}}\right\}^{\mathrm{T}} \\
& =\left\{u_{01}, v_{01}, w_{1}, \varphi_{x 1}, \varphi_{y 1}, \ldots, u_{0 n}, v_{0 n}, w_{n}, \varphi_{x n}, \varphi_{y n}\right\}^{\mathrm{T}}
\end{aligned}
$$

$$
\begin{aligned}
& {[\mathbf{M}]_{I J}=\iint\left[\begin{array}{ccccc}
h & & & \\
& h & & 0 & \\
& h & & \\
& & & \frac{h^{3}}{12} & \\
& 0 & & \\
& & & \frac{h^{3}}{12}
\end{array}\right] \rho H_{I} H_{J} \mathrm{~d} x \mathrm{~d} y,} \\
& \mathbf{K}_{I J}=\iiint_{-h / 2}^{h / 2}\left[\begin{array}{c}
\mathbf{B}_{0 I}^{\mathrm{T}} \\
-z \mathbf{B}_{1 I}^{\mathrm{T}}
\end{array}\right] \mathbf{D}\left[\mathbf{B}_{0 J}-z \mathbf{B}_{1 J}\right] \mathrm{d} z \mathrm{~d} x \mathrm{~d} y \\
& +\iint\left[\begin{array}{c}
\mathbf{0} \\
\mathbf{B}_{2 I}^{\mathrm{T}}
\end{array}\right] \widetilde{\mathbf{A}}_{s}\left[\begin{array}{ll}
\mathbf{0} & \mathbf{B}_{2 J}
\end{array}\right] \mathrm{d} x \mathrm{~d} y \\
& =\iiint_{-h / 2}^{h / 2}\left[\begin{array}{cc}
\mathbf{B}_{0 I}^{\mathrm{T}} \mathbf{D B}_{0 J} & -z \mathbf{B}_{0 I}^{\mathrm{T}} \mathbf{D B}_{1 J} \\
-z \mathbf{B}_{1 I}^{\mathrm{T}} \mathbf{D B}_{0 J} & z^{2} \mathbf{B}_{1 I}^{\mathrm{T}} \mathbf{D B}_{1 J}
\end{array}\right] \mathrm{d} z \mathrm{~d} x \mathrm{~d} y \\
& +\iint\left[\begin{array}{cc}
\mathbf{0} & \mathbf{0} \\
\mathbf{0} & \mathbf{B}_{2 I}^{\mathrm{T}} \widetilde{\mathbf{A}}_{s} \mathbf{B}_{2 J}
\end{array}\right] \mathrm{d} x \mathrm{~d} y .
\end{aligned}
$$

If $(\widetilde{\mathbf{A}}, \widetilde{\mathbf{B}}, \widetilde{\mathbf{H}})=\int_{-h / 2}^{h / 2} \mathbf{D}\left(1, z, z^{2}\right) \mathrm{d} z$, we obtain

$$
\mathbf{K}_{I J}=\iint\left[\begin{array}{cc}
\mathbf{B}_{0 I}^{\mathrm{T}} \widetilde{\mathbf{A}} \mathbf{B}_{0 J} & -\mathbf{B}_{0 I}^{\mathrm{T}} \widetilde{\mathbf{B}} \mathbf{B}_{1 J} \\
-\mathbf{B}_{1 I}^{\mathrm{T}} \widetilde{\mathbf{B}} \mathbf{B}_{0 J} & \mathbf{B}_{1 I}^{\mathrm{T}} \widetilde{\mathbf{H}} \mathbf{B}_{1 J}+\mathbf{B}_{2 I}^{\mathrm{T}} \widetilde{\mathbf{A}}_{s} \mathbf{B}_{2 J}
\end{array}\right] \mathrm{d} x \mathrm{~d} y .
$$

For the symmetric laminates, $\widetilde{\mathbf{B}}=0$.

\section{Formulation for Folded Laminated Plates}

In the paper, a folded laminated plate is regarded as a composite structure composed of laminates. We have obtained the stiffness and mass matrices of a single laminate. Therefore, the next step is to take each laminate of the composite structure as a super element, to superpose their stiffness and mass matrices by applying the displacement compatibility conditions along the joints between the laminates, and to give the governing equation of the entire folded laminated plate (Figure 2).

Nevertheless, as pointed out by the author in [20], due to a lack of Kronecker delta properties in the meshfree shape functions given by (9), and that $\boldsymbol{\delta}$ of (20) are nodal parameters other than actual nodal displacements, the stiffness and mass matrices cannot be directly superposed. The full transformation method that was first introduced by Chen et al. [19] to enforce the essential boundary conditions is extended by the author in the paper to modify the stiffness and mass matrices before a superposition. After the modification, the essential boundary conditions can be implemented as those in FEMs.

4.1. Modification of Stiffness and Mass Matrices. From (1), the actual displacement of the nodes, $\overline{\mathbf{v}}(\mathbf{x})$, can be approximated by $\mathbf{v}^{d}(\mathbf{x})$

$$
\overline{\mathbf{v}}(\mathbf{x}) \approx \mathbf{v}^{d}(\mathbf{x})=\sum_{I=1}^{n} N_{I}(\mathbf{x}) v_{I}=\boldsymbol{\Phi} \mathbf{v}
$$




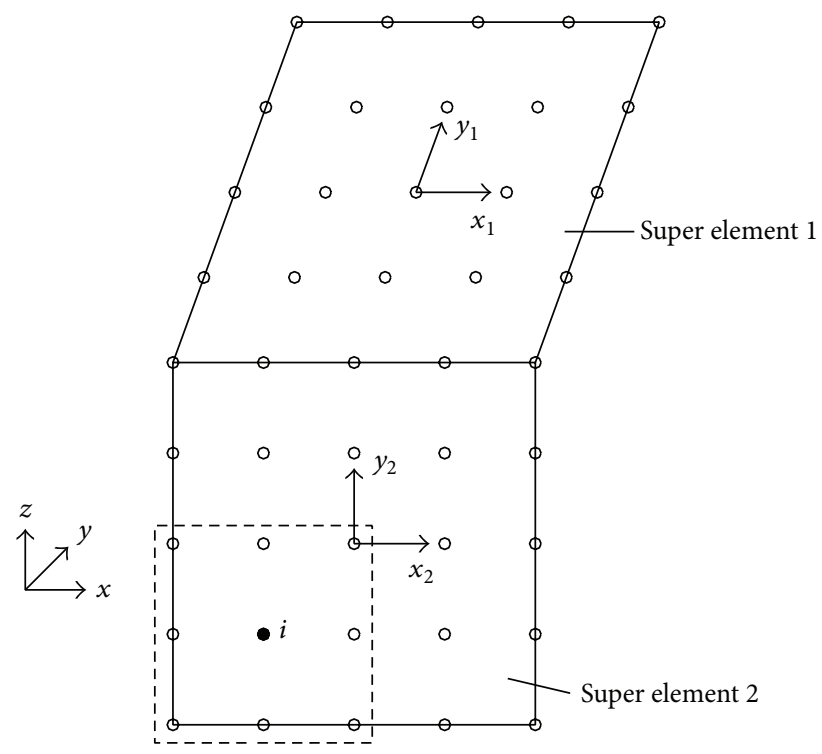

FIGURE 2: A meshfree model of a folded laminated plate that is made up of two super elements (laminates). The domain of influence of node $i$ is indicated by the dashed line.

where

$$
\boldsymbol{\Phi}=\left[\begin{array}{cccc}
N_{1}\left(\mathbf{x}_{1}\right) & N_{2}\left(\mathbf{x}_{1}\right) & \ldots & N_{n}\left(\mathbf{x}_{1}\right) \\
N_{1}\left(\mathbf{x}_{2}\right) & N_{2}\left(\mathbf{x}_{2}\right) & \ldots & N_{n}\left(\mathbf{x}_{2}\right) \\
\vdots & \vdots & \vdots & \vdots \\
N_{1}\left(\mathbf{x}_{n}\right) & N_{2}\left(\mathbf{x}_{n}\right) & \ldots & N_{n}\left(\mathbf{x}_{n}\right)
\end{array}\right]
$$

and $v_{I}$ are the nodal parameters. Therefore, the nodal parameters can be expressed in terms of the actual displacement

$$
\mathbf{v}=\Lambda \overline{\mathbf{v}}
$$

where $\Lambda=\Phi^{-1}$.

For the folded laminated plate, we accordingly have

$$
\begin{array}{lll}
\mathbf{u}_{0}=\Lambda \overline{\mathbf{u}}_{0}, & \mathbf{v}_{0}=\Lambda \overline{\mathbf{v}}_{0}, & \mathbf{w}=\Lambda \overline{\mathbf{w}}, \\
\varphi_{x}=\Lambda \bar{\varphi}_{x}, & \varphi_{y}=\Lambda \bar{\varphi}_{y}, &
\end{array}
$$

where $\overline{\mathbf{u}}_{0}=\left\{\bar{u}_{0}\left(\mathbf{x}_{1}\right), \bar{u}_{0}\left(\mathbf{x}_{2}\right), \ldots, \bar{u}_{0}\left(\mathbf{x}_{n}\right)\right\}^{\mathrm{T}}=\left\{\bar{u}_{01}, \bar{u}_{02}, \ldots, \bar{u}_{0 n}\right\}^{\mathrm{T}}$ are the actual nodal displacement (translation) in the $x$ direction and $\mathbf{u}_{0}=\left\{u_{01}, u_{02}, \ldots, u_{0 n}\right\}^{\mathrm{T}}$ are the corresponding nodal parameters. $\mathbf{v}_{0}, \overline{\mathbf{v}}_{0}, \mathbf{w}, \overline{\mathbf{w}}, \boldsymbol{\varphi}_{x}, \overline{\boldsymbol{\varphi}}_{x}, \boldsymbol{\varphi}_{y}$, and $\overline{\boldsymbol{\varphi}}_{y}$ have similar definition. Equation (26) can be written as

$$
\delta=\bar{\Lambda} \bar{\delta},
$$

where $\overline{\boldsymbol{\delta}}=\left\{\overline{\boldsymbol{\delta}}_{1}^{\mathrm{T}} \overline{\boldsymbol{\delta}}_{2}^{\mathrm{T}} \ldots \overline{\boldsymbol{\delta}}_{n}^{\mathrm{T}}\right\}^{\mathrm{T}}=\left\{\bar{u}_{01}, \bar{v}_{01}, \bar{w}_{1}, \bar{\varphi}_{x 1}, \bar{\varphi}_{y 1}, \ldots\right.$, $\left.\bar{u}_{0 n}, \bar{v}_{0 n}, \bar{w}_{n}, \bar{\varphi}_{x n}, \bar{\varphi}_{y n}\right\}^{\mathrm{T}}$ are the actual nodal displacement of all nodes. $\bar{\Lambda}$ is a $5 n \times 5 n$ modification matrix which combines five $\Lambda$. Substituting (27) into (20) and premultiplying both sides of the equation with $\bar{\Lambda}^{\mathrm{T}}$, we obtain

$$
\overline{\boldsymbol{\Lambda}}^{\mathrm{T}} \mathbf{K} \overline{\boldsymbol{\Lambda}} \overline{\boldsymbol{\delta}}+\overline{\boldsymbol{\Lambda}}^{\mathrm{T}} \mathbf{M} \overline{\boldsymbol{\Lambda}} \ddot{\overline{\boldsymbol{\delta}}}=\mathbf{0} .
$$

Assuming that $\overline{\mathbf{K}}=\overline{\boldsymbol{\Lambda}}^{\mathrm{T}} \mathbf{K} \overline{\boldsymbol{\Lambda}}$ and $\overline{\mathbf{M}}=\overline{\boldsymbol{\Lambda}}^{\mathrm{T}} \mathbf{M} \overline{\boldsymbol{\Lambda}}$, we have

$$
\overline{\mathbf{K}} \overline{\boldsymbol{\delta}}+\overline{\mathbf{M}} \ddot{\bar{\delta}}=\mathbf{0},
$$

the modified governing equation.

4.2. The Governing Equation of the Folded Laminated Plate. Because the stiffness and mass matrices of a laminate in (20) were established in a local coordinate attached to the laminate (Figure 1), the matrices in (29) need to be transformed to the global coordinates before the superposition. The stiffness and mass matrices and the nodal displacement in the global coordinates are

$$
\widetilde{\mathbf{K}}=\mathbf{T} \overline{\mathbf{K}} \mathbf{T}^{\mathrm{T}}, \quad \widetilde{\mathbf{M}}=\mathbf{T} \overline{\mathbf{M}} \mathbf{T}^{\mathrm{T}}, \quad \widetilde{\boldsymbol{\delta}}=\mathbf{T} \overline{\boldsymbol{\delta}},
$$

where $\mathbf{T}$ is the $6 n \times 6 n$ coordinate transformation matrix derived in [20] (note: a drilling degree of freedom $\varphi_{z}$ has been added to $\overline{\boldsymbol{\delta}}$, and $\overline{\mathbf{K}}$ and $\overline{\mathbf{M}}$ must be expanded accordingly by inserting some zero elements). If there are $J$ (no. 1 to $J$ ) coincident nodes along the joint between super elements 1 and 2 (Figure 2), we have

$$
\tilde{\boldsymbol{\delta}}_{b}^{1}=\widetilde{\boldsymbol{\delta}}_{b}^{2}, \quad \ddot{\widetilde{\boldsymbol{\delta}}}_{b}^{1}=\ddot{\widetilde{\boldsymbol{\delta}}}_{b}^{2}
$$

where $\widetilde{\boldsymbol{\delta}}_{b}^{1}=\left\{\tilde{u}_{01}^{1}, \widetilde{v}_{01}^{1}, \widetilde{w}_{1}^{1}, \widetilde{\varphi}_{x 1}^{1}, \widetilde{\varphi}_{y 1}^{1}, \widetilde{\varphi}_{z 1}^{1}, \ldots, \widetilde{u}_{0 J}^{1}, \widetilde{v}_{0 J}^{1}, \widetilde{w}_{J}^{1}, \widetilde{\varphi}_{x J}^{1}, \widetilde{\varphi}_{y J}^{1}\right.$, $\left.\tilde{\varphi}_{z J}^{1}\right\}^{\mathrm{T}}$ are the actual displacement of the nodes of super element 1 along the joint between super element 1 and super element 2 and $\widetilde{\boldsymbol{\delta}}_{b}^{2}=\left\{\tilde{u}_{01}^{2}, \widetilde{v}_{01}^{2}, \widetilde{w}_{1}^{2}, \widetilde{\varphi}_{x 1}^{2}, \widetilde{\varphi}_{y 1}^{2}, \widetilde{\varphi}_{z 1}^{2}, \ldots, \widetilde{u}_{0 J}^{2}, \widetilde{v}_{0 J}^{2}\right.$, $\left.\widetilde{w}_{J}^{2}, \tilde{\varphi}_{x J}^{2}, \tilde{\varphi}_{y J}^{2}, \tilde{\varphi}_{z J}^{2}\right\}^{\mathrm{T}}$ are the actual displacement of the nodes of super element 2 along the joint between super element 1 and super element 2. After necessary elementary transformation, the governing equation of super elements 1 and 2 can be written in block forms

$$
\begin{gathered}
{\left[\begin{array}{cc}
\widetilde{\mathbf{k}}_{i i}^{1} & \widetilde{\mathbf{k}}_{i b}^{1} \\
\widetilde{\mathbf{k}}_{b i}^{1} & \widetilde{\mathbf{k}}_{b b}^{1}
\end{array}\right]\left\{\begin{array}{c}
\widetilde{\boldsymbol{\delta}}_{i}^{1} \\
\widetilde{\boldsymbol{\delta}}_{b}^{1}
\end{array}\right\}+\left[\begin{array}{cc}
\widetilde{\mathbf{m}}_{i i}^{1} & \widetilde{\mathbf{m}}_{i b}^{1} \\
\widetilde{\mathbf{m}}_{b i}^{1} & \widetilde{\mathbf{m}}_{b b}^{1}
\end{array}\right]\left\{\begin{array}{c}
\ddot{\widetilde{\boldsymbol{\delta}}}_{i}^{1} \\
\ddot{\widetilde{\boldsymbol{\delta}}}_{b}^{1}
\end{array}\right\}=\mathbf{0},} \\
{\left[\begin{array}{cc}
\widetilde{\mathbf{k}}_{b b}^{2} & \widetilde{\mathbf{k}}_{b i}^{2} \\
\widetilde{\mathbf{k}}_{i b}^{2} & \widetilde{\mathbf{k}}_{i i}^{2}
\end{array}\right]\left\{\begin{array}{c}
\widetilde{\boldsymbol{\delta}}_{b}^{2} \\
\widetilde{\boldsymbol{\delta}}_{i}^{2}
\end{array}\right\}+\left[\begin{array}{cc}
\widetilde{\mathbf{m}}_{b b}^{2} & \widetilde{\mathbf{m}}_{b i}^{2} \\
\widetilde{\mathbf{m}}_{i b}^{2} & \widetilde{\mathbf{m}}_{i i}^{2}
\end{array}\right]\left\{\begin{array}{c}
\ddot{\boldsymbol{\delta}}_{b}^{2} \\
\ddot{\boldsymbol{\delta}}_{i}^{2}
\end{array}\right\}=\mathbf{0},}
\end{gathered}
$$

where $\widetilde{\boldsymbol{\delta}}_{i}^{1}$ and $\widetilde{\boldsymbol{\delta}}_{i}^{2}$ are the actual displacement of the nodes of super elements 1 and 2 that are not along the joint, respectively. Equation (32) are supposed to give the equation governing the dynamic behaviors of the entire structure

$$
\begin{aligned}
& {\left[\begin{array}{ccc}
\widetilde{\mathbf{k}}_{i i}^{1} & \widetilde{\mathbf{k}}_{i b}^{1} & \mathbf{0} \\
\widetilde{\mathbf{k}}_{b i}^{1} & \widetilde{\mathbf{k}}_{b b}^{1}+\widetilde{\mathbf{k}}_{b b}^{2} & \widetilde{\mathbf{k}}_{b i}^{2} \\
\mathbf{0} & \widetilde{\mathbf{k}}_{i b}^{2} & \widetilde{\mathbf{k}}_{i i}^{2}
\end{array}\right]\left\{\begin{array}{c}
\widetilde{\boldsymbol{\delta}}_{i}^{1} \\
\widetilde{\boldsymbol{\delta}}_{b}^{1} \\
\widetilde{\boldsymbol{\delta}}_{i}^{2}
\end{array}\right\}} \\
& +\left[\begin{array}{ccc}
\widetilde{\mathbf{m}}_{i i}^{1} & \widetilde{\mathbf{m}}_{i b}^{1} & \mathbf{0} \\
\widetilde{\mathbf{m}}_{b i}^{1} & \widetilde{\mathbf{m}}_{b b}^{1}+\widetilde{\mathbf{m}}_{b b}^{2} & \widetilde{\mathbf{m}}_{b i}^{2} \\
\mathbf{0} & \widetilde{\mathbf{m}}_{i b}^{2} & \widetilde{\mathbf{m}}_{i i}^{2}
\end{array}\right]\left\{\begin{array}{c}
\ddot{\tilde{\boldsymbol{\delta}}}_{i}^{1} \\
\ddot{\widetilde{\boldsymbol{\delta}}}_{b}^{1} \\
\ddot{\widetilde{\boldsymbol{\delta}}}_{i}^{2}
\end{array}\right\}=\mathbf{0 .}
\end{aligned}
$$


Taking

$$
\begin{gathered}
\mathbf{K}_{G}=\left[\begin{array}{ccc}
\widetilde{\mathbf{k}}_{i i}^{1} & \widetilde{\mathbf{k}}_{i b}^{1} & \mathbf{0} \\
\widetilde{\mathbf{k}}_{b i}^{1} & \widetilde{\mathbf{k}}_{b b}^{1}+\widetilde{\mathbf{k}}_{b b}^{2} & \widetilde{\mathbf{k}}_{b i}^{2} \\
\mathbf{0} & \widetilde{\mathbf{k}}_{i b}^{2} & \widetilde{\mathbf{k}}_{i i}^{2}
\end{array}\right], \\
\mathbf{M}_{G}=\left[\begin{array}{ccc}
\widetilde{\mathbf{m}}_{i i}^{1} & \widetilde{\mathbf{m}}_{i b}^{1} & \mathbf{0} \\
\widetilde{\mathbf{m}}_{b i}^{1} & \widetilde{\mathbf{m}}_{b b}^{1}+\widetilde{\mathbf{m}}_{b b}^{2} & \widetilde{\mathbf{m}}_{b i}^{2} \\
\mathbf{0} & \widetilde{\mathbf{m}}_{i b}^{2} & \widetilde{\mathbf{m}}_{i i}^{2}
\end{array}\right], \\
\boldsymbol{\delta}_{G}=\left\{\begin{array}{l}
\widetilde{\boldsymbol{\delta}}_{i}^{1} \\
\widetilde{\boldsymbol{\delta}}_{b}^{1} \\
\widetilde{\boldsymbol{\delta}}_{i}^{2}
\end{array}\right\},
\end{gathered}
$$

we have

$$
\mathbf{K}_{G} \boldsymbol{\delta}_{G}+\mathbf{M}_{G} \ddot{\boldsymbol{\delta}}_{G}=\mathbf{0}
$$

The solution of the corresponding eigenvalue problem

$$
\left(\mathbf{K}_{G}-\omega^{2} \mathbf{M}_{G}\right) \boldsymbol{\delta}_{0}=\mathbf{0}
$$

gives us the free vibration frequencies of the folded laminated plate.

\section{Results and Discussion}

In order to show the convergence and accuracy of the proposed method, several numerical examples are calculated with the method and the finite element software ANSYS. For all the laminates in the examples, the plies are assumed to have the same thickness and material properties: $E_{1}=2.5 \times$ $10^{7} \mathrm{~Pa}, E_{2}=1 \times 10^{6} \mathrm{~Pa}, G_{12}=G_{13}=5 \times 10^{5} \mathrm{~Pa}$, $G_{23}=2 \times 10^{5} \mathrm{~Pa}, \mu_{12}=0.25$, and $\rho=2823 \mathrm{~kg} / \mathrm{m}^{3}$. Unless otherwise specified, for each example a total of two cases of symmetric laminates, cross-ply or angle-ply, which make up the folded plates, are studied: $\left(0^{\circ} / 90^{\circ} / 90^{\circ} / 0^{\circ}\right)$ and $\left(-45^{\circ} / 45^{\circ} /\right.$ $\left.-45^{\circ} / 45^{\circ} /-45^{\circ} \ldots\right)_{10}$. In ANSYS, the folded laminated plates in the examples are all modeled as shells, and the linear layered structural shell element SHELL99 [29] is used to discretise the folded plates.

5.1. Validation Studies. To carry out the validation studies, a cantilever square laminate with a lamination scheme of $\left(-45^{\circ} / 45^{\circ} / 45^{\circ} /-45^{\circ}\right)$ is considered (Figure 3$)$. The width of the plate is $1.8 \mathrm{~m}$, and the thickness is $0.018 \mathrm{~m}$. The solution from ANSYS (5000 elements to discretise the laminate) is taken to be the exact solution. The validation studies consist of a convergence study and a study on the effect of the size of support and the completeness order of the basis functions on the convergence of solutions.

Firstly, we choose a certain meshless scheme $(11 \times 11$ nodes for the laminate) and let the scaling factor $\beta$ and the completeness order $N_{c}$ of the basis function vary. $\beta$ defines

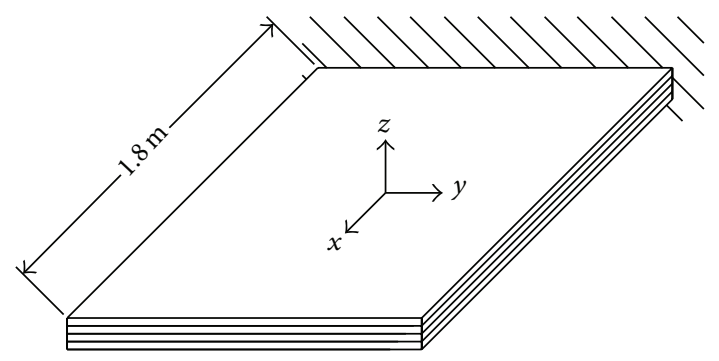

Figure 3: A cantilevered laminate.

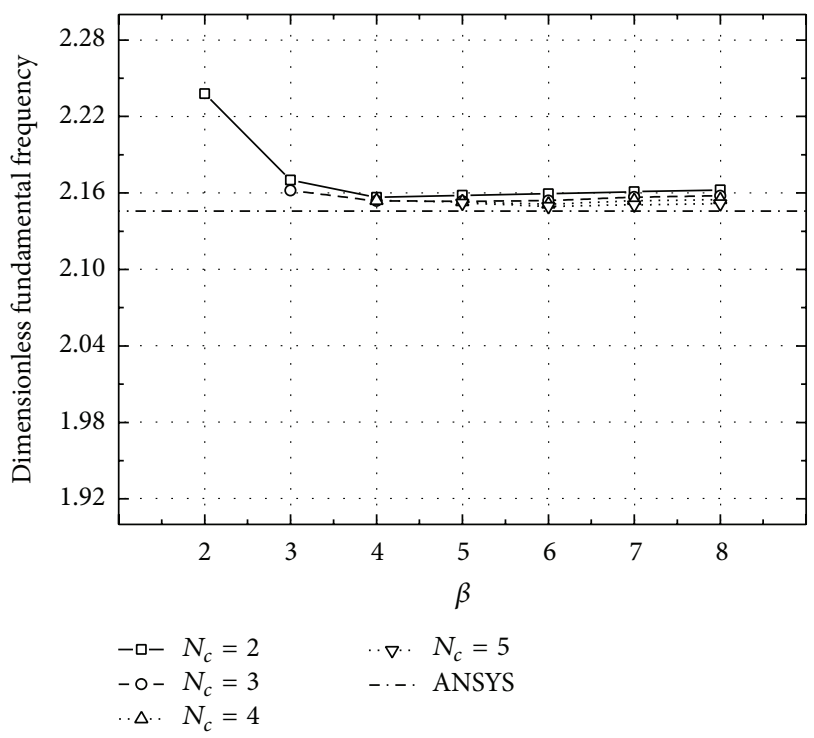

FIGURE 4: Variation of dimensionless fundamental frequency of the laminate under different $\beta$ and $N_{c}$.

the size of the support of nodes. In this paper, a rectangular support is used and

$$
\begin{aligned}
& h_{x}=\beta \cdot I_{x}, \\
& h_{y}=\beta \cdot I_{y},
\end{aligned}
$$

where $h_{x}, h_{y}$ are the lengths of the support in the $x$ and $y$ directions, respectively, and $I_{x}, I_{y}$ are the distances between two neighbouring nodes in the $x$-and $y$-directions, respectively. The dimensionless fundamental frequency of the laminate as calculated by the proposed method under different values of $\beta$ and $N_{c}$ is shown in Figure 4 and is compared with the solution that is given by ANSYS. The dimensionless frequency is defined as

$$
\bar{\omega}=\omega\left(\frac{L^{2}}{h}\right) \sqrt{\left(\frac{\rho}{E_{2}}\right)},
$$

where $L$ is the width of the laminate and $\omega$ is the vibration frequency. From Figure 4, it can be observed that for a certain meshless scheme (in this case $11 \times 11$ nodes), all of the solutions for different completeness orders $\left(N_{c}\right)$ of the basis functions converge when the support size $(\beta)$ is larger than 5 . Higher completeness orders $\left(N_{c}\right)$ need a larger support size 


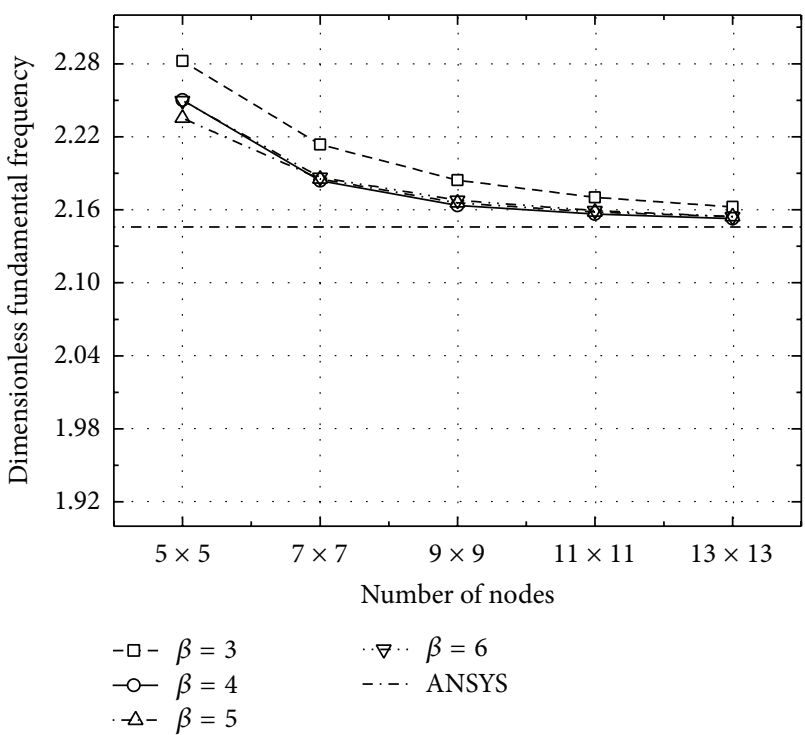

FIGURE 5: Variation of dimensionless fundamental frequency of the laminate, $N_{c}=2$.

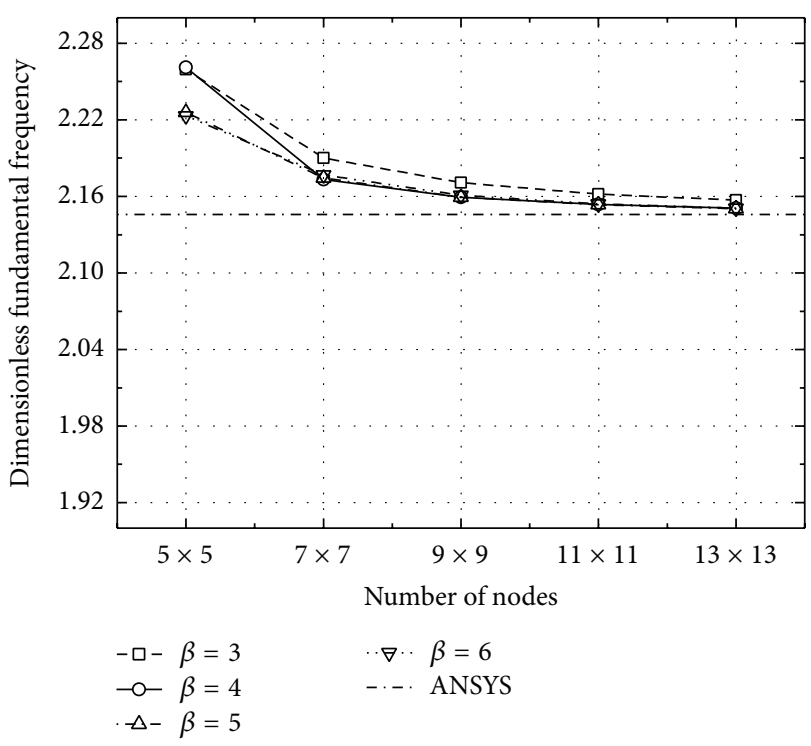

FIGURE 6: Variation of dimensionless fundamental frequency of the laminate, $N_{c}=3$.

to make the solution converge (the solution under $N_{c}=2$ converges at $\beta=4$ while the solution under $N_{c}=5$ converges at $\beta=5$ ).

Secondly, we vary the meshless scheme and obtain the variations of the dimensionless fundamental frequency under certain completeness order of the basis functions $\left(N_{c}\right)$, which are shown in Figures 5, 6, 7, and 8, respectively. The solution that is given by ANSYS is also in the figures for comparison. Figures 5 to 8 indicate that for certain $\beta$, the solution converges when the number of nodes increases. For an $N_{c}$, the solutions for larger support sizes $(\beta)$ converge before those for smaller support sizes do.

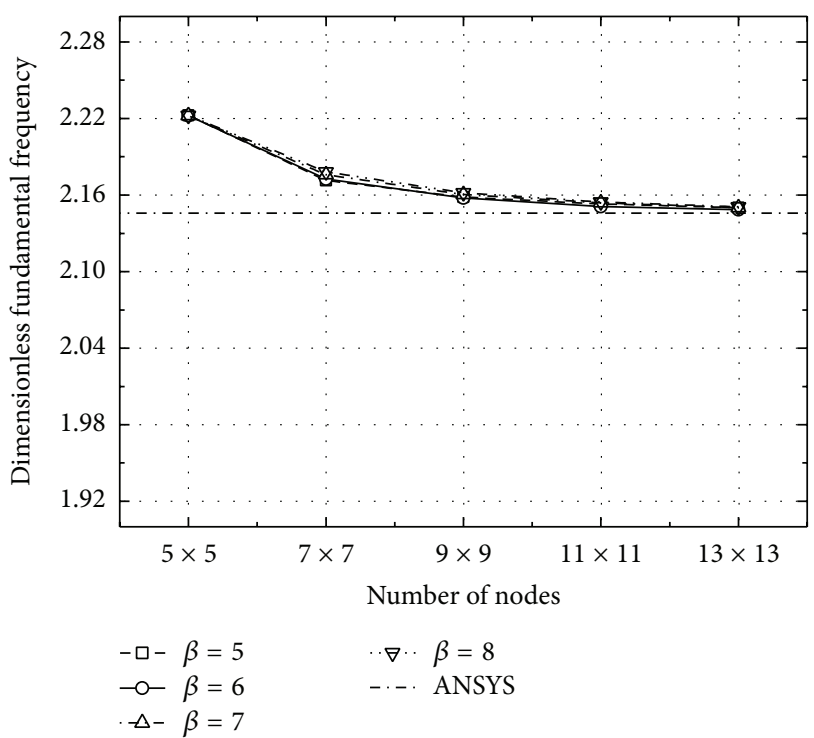

FIGURE 7: Variation of dimensionless fundamental frequency of the laminate, $N_{c}=4$.

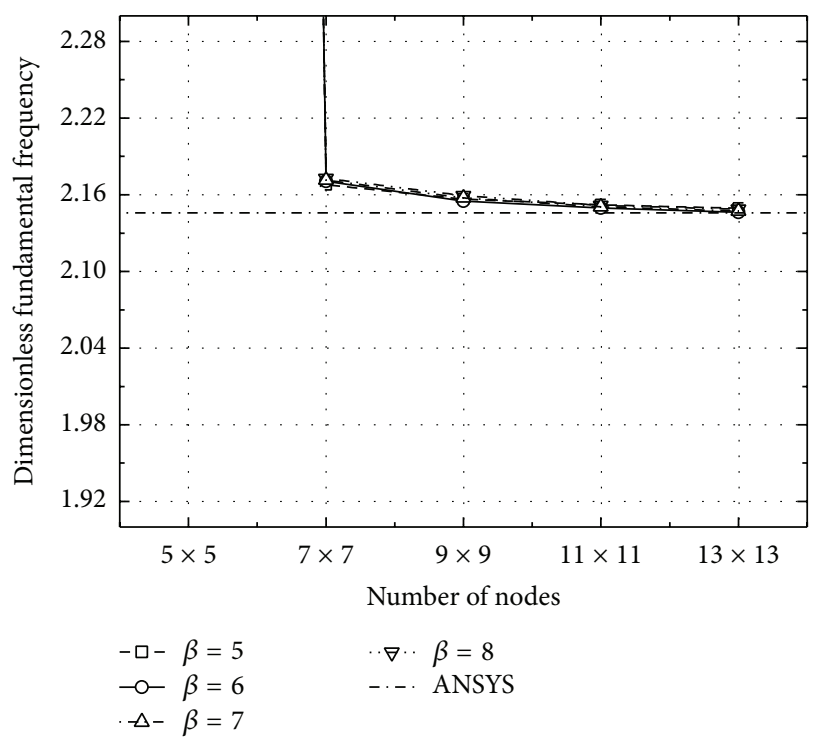

FIGURE 8: Variation of dimensionless fundamental frequency of the laminate, $N_{c}=5$.

From the studies, we find that when the order of basis functions $N_{c}=2$ and the support size $\beta=4$ for the laminate, the solutions are precise enough with a relatively lower computational cost. Therefore, all of the following examples are calculated with $N_{c}=2, \beta=4$.

5.2. A Folded Plate That Is Made Up of Two Laminates. A clamped laminated folded plate that is made up of two identical square laminates is studied (Figure 9). The width of each laminate is $L=1 \mathrm{~m}$, and the thickness $h=0.012 \mathrm{~m}$. The dimensionless frequencies of the first five vibration modes of the folded plate that are obtained by the proposed method $(11 \times 11$ nodes for each laminate $)$ are listed in Tables 1 and 2 
TABLE 1: Dimensionless free vibration frequencies of the onefold laminated plate with the lamination scheme $\left(0^{\circ} / 90^{\circ} / 90^{\circ} / 0^{\circ}\right)$

\begin{tabular}{lcccc}
\hline Crank angle & Modes & $\begin{array}{c}\text { Present } \\
\text { results }\end{array}$ & $\begin{array}{c}\text { ANSYS } \\
\text { results }\end{array}$ & $\begin{array}{c}\text { Relative } \\
\text { errors }\end{array}$ \\
\hline \multirow{3}{*}{$\alpha=90^{\circ}$} & 1 & 8.9128 & 8.89037 & $0.25 \%$ \\
& 2 & 10.0977 & 10.06576 & $0.32 \%$ \\
& 3 & 12.9276 & 12.87695 & $0.39 \%$ \\
& 4 & 13.8224 & 13.77692 & $0.33 \%$ \\
$\alpha=150^{\circ}$ & 5 & 28.836 & 28.70447 & $0.46 \%$ \\
\hline & 1 & 8.91325 & 8.89121 & $0.25 \%$ \\
& 2 & 10.1036 & 10.06659 & $0.37 \%$ \\
& 4 & 12.9008 & 12.8508 & $0.39 \%$ \\
& 5 & 13.7894 & 13.74465 & $0.33 \%$ \\
& 5 & 28.841 & 28.71003 & $0.46 \%$ \\
\hline
\end{tabular}

TABle 2: Dimensionless free vibration frequencies of the onefold laminated plate with the lamination scheme $\left(-45^{\circ} / 45^{\circ} /-45^{\circ} / 45^{\circ} /-45^{\circ} \ldots\right)_{10}$.

\begin{tabular}{lcccc}
\hline Crank angle & Modes & $\begin{array}{c}\text { Present } \\
\text { results }\end{array}$ & $\begin{array}{c}\text { ANSYS } \\
\text { results }\end{array}$ & $\begin{array}{c}\text { Relative } \\
\text { errors }\end{array}$ \\
\hline \multirow{3}{*}{$\alpha=90^{\circ}$} & 1 & 10.5522 & 10.48862 & $0.61 \%$ \\
& 2 & 15.7311 & 15.63222 & $0.63 \%$ \\
& 3 & 19.2923 & 19.11888 & $0.91 \%$ \\
& 4 & 22.6269 & 22.45392 & $0.77 \%$ \\
$\alpha=150^{\circ}$ & 5 & 35.233 & 34.9528 & $0.80 \%$ \\
\hline & 1 & 10.5784 & 10.49001 & $0.84 \%$ \\
& 2 & 15.4292 & 15.32843 & $0.66 \%$ \\
& 3 & 19.5467 & 19.09968 & $2.34 \%$ \\
& 4 & 21.6468 & 21.4844 & $0.76 \%$ \\
& 5 & 35.3159 & 34.97227 & $0.98 \%$ \\
\hline
\end{tabular}

alongside the results that are given by ANSYS (3200 elements to discretise the folded plate) for comparison, and the first five mode shapes of vibration of the folded plate are also plotted graphically in Figures 10 and 11. Different crank angles of the folded plate, $\alpha=90^{\circ}$ and $\alpha=150^{\circ}$, are considered. The results of the two methods are very close.

When the folded plate is clamped at one side, which makes it a cantilevered folded plate (Figure 12), the dimensionless frequencies of the first five vibration modes of the structure are listed in Tables 3 and 4, and the five vibration mode shapes are shown in Figures 13 and 14.

5.3. A Folded Plate That Is Made Up of Three Laminates. A folded plate that is made up of three identical square laminates and clamped at one side is studied (Figure 15, $\alpha=$ $90^{\circ}$ ). The width of each laminate is $L=1 \mathrm{~m}$, and the thickness $h=0.01 \mathrm{~m}$. The dimensionless frequencies of the first five vibration modes of the folded plate, which are calculated with the proposed method and ANSYS, are listed in Tables 5 and 6 , and the first five mode shapes of vibration of the folded plate are also plotted graphically in Figures 16 and 17. In

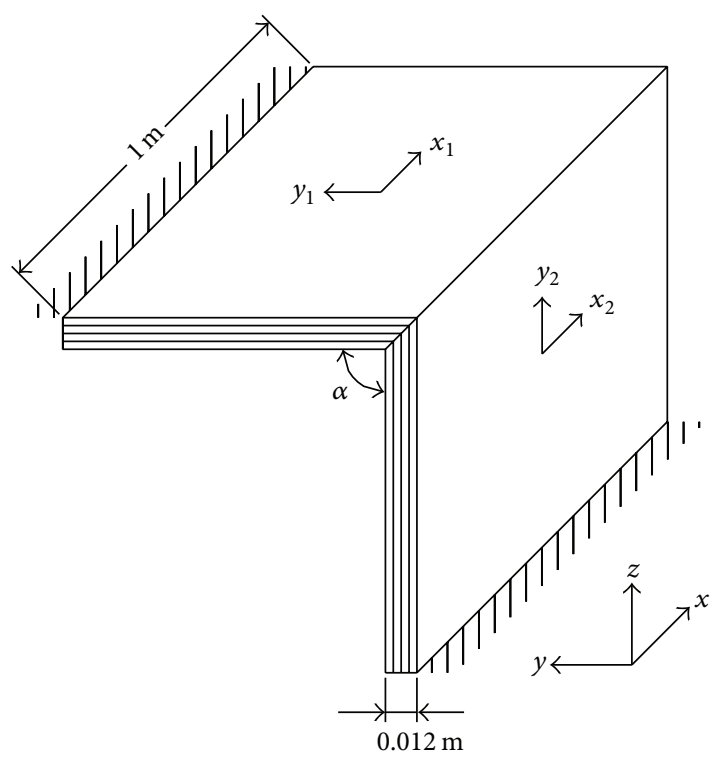

FIgURE 9: The onefold laminated plate with two sides fixed.

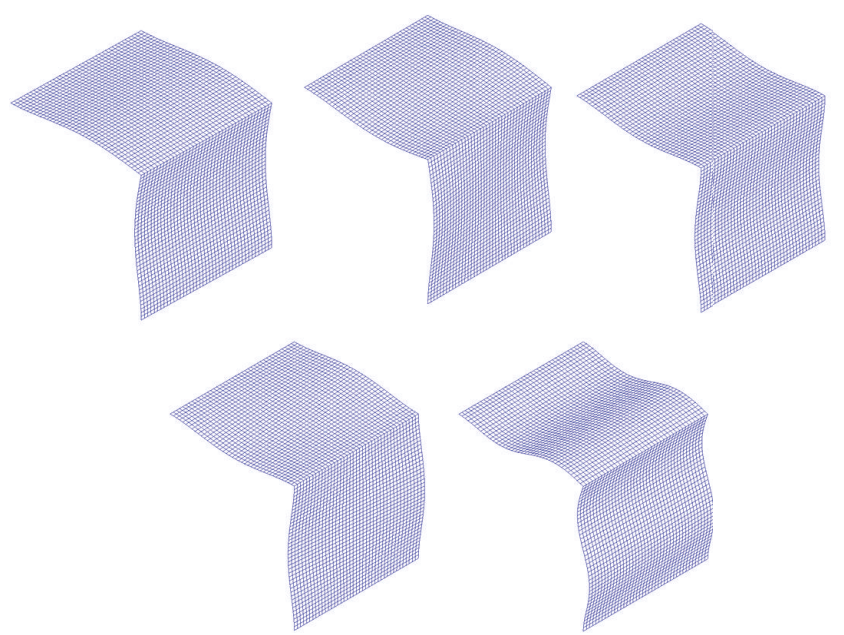

FIGURE 10: First five vibration mode shapes of the clamped folded plate $\left(\alpha=90^{\circ}\right)$.

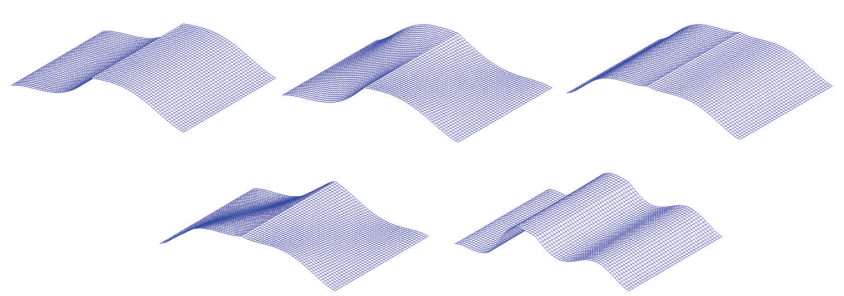

FIGURE 11: First five vibration mode shapes of the clamped folded plate $\left(\alpha=150^{\circ}\right)$.

ANSYS, 4800 elements are used to discretise the structure. The agreement between the two sets of results is good.

When the crank angle $\alpha=60^{\circ}$ and the laminates are assumed to be connected with one another, we obtain a tub structure with three folds (Figure 18). The dimensionless frequencies of the first five vibration modes of the structure 


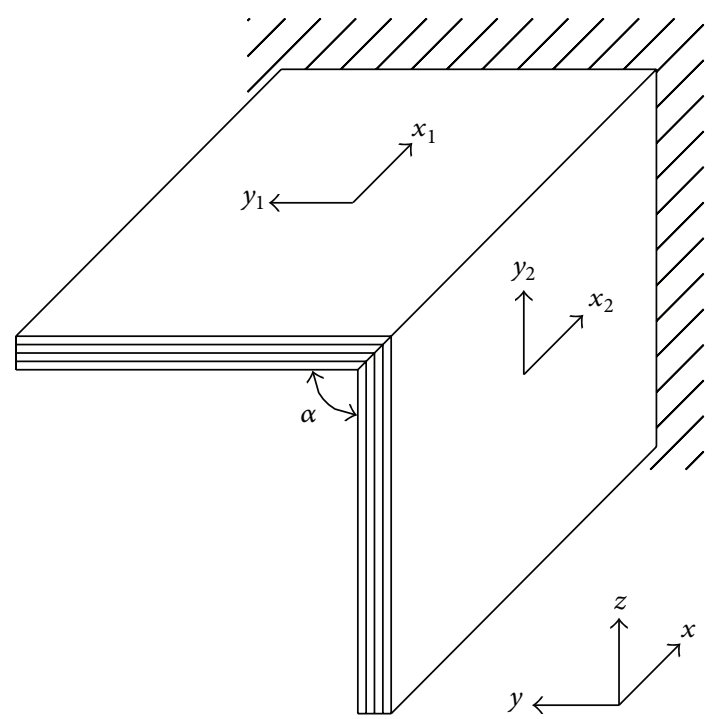

FIGURE 12: The cantilevered onefold laminated plate.

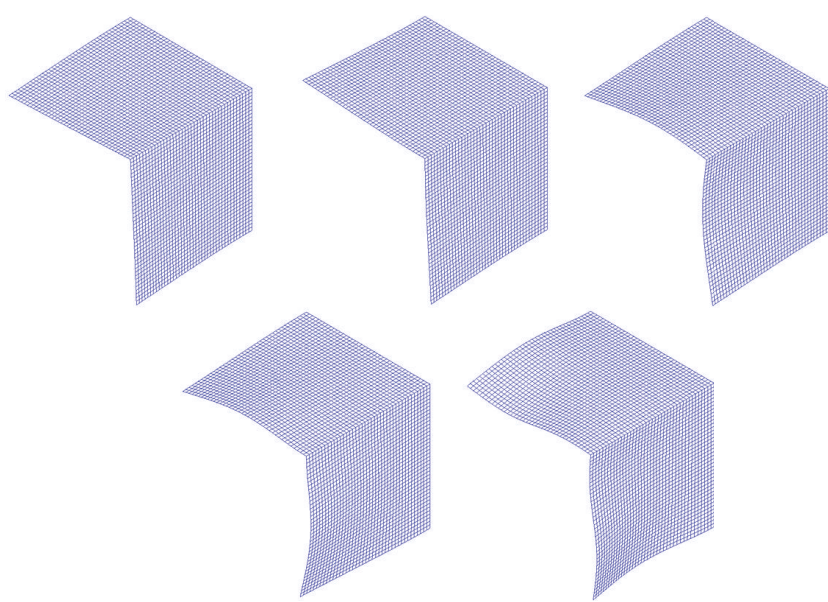

FIGURE 13: First five vibration mode shapes of the cantilevered folded plate $\left(\alpha=90^{\circ}\right)$.

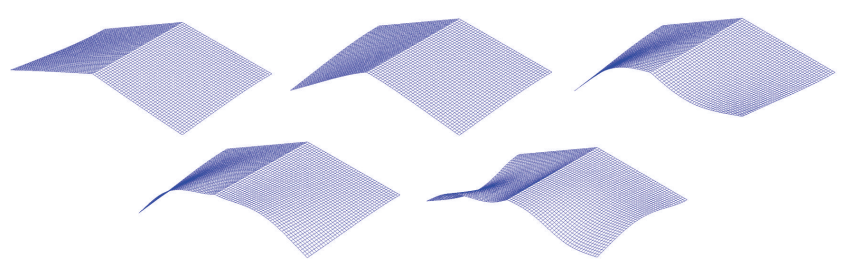

FIGURE 14: First five vibration mode shapes of the cantilevered folded plate $\left(\alpha=150^{\circ}\right)$.

are listed in Tables 7 and 8 , and the first five mode shapes are shown in Figure 19.

5.4. A Laminated Shell. If the three laminates in Section 5.3 are joined with each other vertically, we obtain a laminated shell (or half of a box structure) (Figure 20). The structure is pinned at points $A, B$, and C. All of the DOFs, except the rotations of these points, are set to zero.

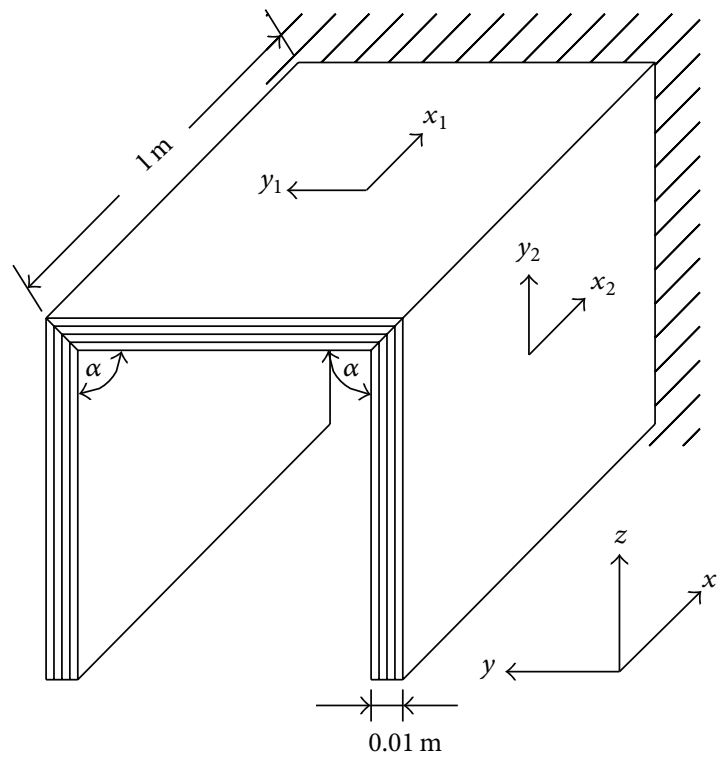

Figure 15: A cantilevered folded plate that is made up of three identical square laminates.

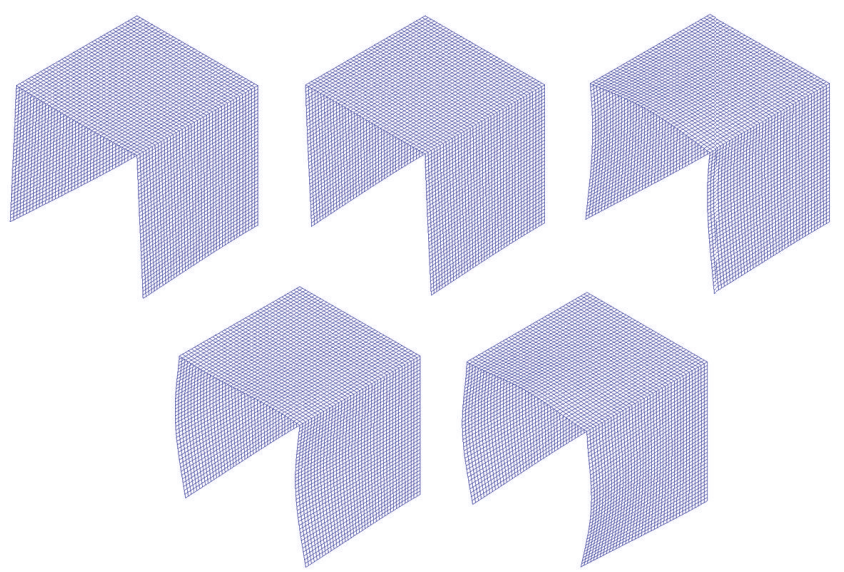

FIGURE 16: First five vibration mode shapes of the cantilevered folded plate $\left(\alpha=90^{\circ}\right)$ that is made up of three identical square laminates.

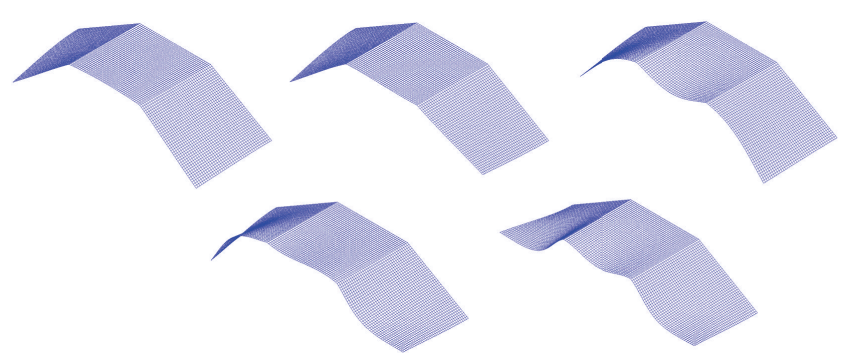

FIGURE 17: First five vibration mode shapes of the cantilevered folded plate $\left(\alpha=150^{\circ}\right)$ that is made up of three identical square laminates.

Three lamination schemes are considered. Case 1: laminate 1 is taken to be $\left(45^{\circ} /-45^{\circ} /-45^{\circ} / 45^{\circ}\right)$ and laminates 2 and 3 to be $\left(-45^{\circ} / 45^{\circ} / 45^{\circ} /-45^{\circ}\right)$, as is demonstrated in Figure $21(\mathrm{a})$; Case 2: laminate 1 is taken to be $\left(-45^{\circ} / 45^{\circ} / 45^{\circ} /-45^{\circ}\right)$ and 
TABLE 3: Dimensionless free vibration frequencies of the cantilevered onefold laminated plate with the lamination scheme $\left(0^{\circ} / 90^{\circ} / 90^{\circ} / 0^{\circ}\right)$.

\begin{tabular}{lcccc}
\hline Crank angle & Modes & $\begin{array}{c}\text { Present } \\
\text { results }\end{array}$ & $\begin{array}{c}\text { ANSYS } \\
\text { results }\end{array}$ & $\begin{array}{c}\text { Relative } \\
\text { errors }\end{array}$ \\
\hline \multirow{2}{*}{$\alpha=90^{\circ}$} & 1 & 4.97836 & 4.97752 & $0.02 \%$ \\
& 2 & 5.47994 & 5.47883 & $0.02 \%$ \\
& 3 & 10.9922 & 10.97741 & $0.13 \%$ \\
& 4 & 14.3614 & 14.32497 & $0.25 \%$ \\
$\alpha=150^{\circ}$ & 5 & 29.6419 & 29.62531 & $0.06 \%$ \\
\hline & 1 & 4.97887 & 4.97752 & $0.03 \%$ \\
& 3 & 5.47507 & 5.47410 & $0.02 \%$ \\
& 4 & 11.0002 & 10.98326 & $0.15 \%$ \\
& 5 & 14.0093 & 13.97611 & $0.24 \%$ \\
& 29.6493 & 29.63643 & $0.04 \%$ \\
\hline
\end{tabular}

TABLE 4: Dimensionless free vibration frequencies of the cantilevered onefold laminated plate with the lamination scheme $\left(-45^{\circ}\right.$ / $\left.45^{\circ} /-45^{\circ} / 45^{\circ} /-45^{\circ} \ldots\right)_{10}$.

\begin{tabular}{lcccc}
\hline Crank angle & Modes & $\begin{array}{c}\text { Present } \\
\text { results }\end{array}$ & $\begin{array}{c}\text { ANSYS } \\
\text { results }\end{array}$ & $\begin{array}{c}\text { Relative } \\
\text { errors }\end{array}$ \\
\hline \multirow{2}{*}{$\alpha=90^{\circ}$} & 1 & 5.19091 & 5.16586 & $0.48 \%$ \\
& 2 & 6.37998 & 6.35766 & $0.35 \%$ \\
& 3 & 15.5232 & 15.42413 & $0.64 \%$ \\
& 4 & 18.0588 & 17.93153 & $0.71 \%$ \\
& 5 & 20.3733 & 20.27757 & $0.47 \%$ \\
\hline & 1 & 5.23049 & 5.16336 & $1.30 \%$ \\
& 2 & 6.30941 & 6.27921 & $0.48 \%$ \\
& 3 & 15.6594 & 15.4258 & $1.51 \%$ \\
& 4 & 17.6398 & 17.50867 & $0.75 \%$ \\
& 5 & 20.2856 & 20.15211 & $0.66 \%$ \\
\hline
\end{tabular}

TABLE 5: Dimensionless free vibration frequencies of the cantilevered twofold laminated plate with the lamination scheme $\left(0^{\circ} /\right.$ $\left.90^{\circ} / 90^{\circ} / 0^{\circ}\right)$.

\begin{tabular}{lcccc}
\hline Crank angle & Modes & $\begin{array}{c}\text { Present } \\
\text { results }\end{array}$ & $\begin{array}{c}\text { ANSYS } \\
\text { results }\end{array}$ & $\begin{array}{c}\text { Relative } \\
\text { errors }\end{array}$ \\
\hline \multirow{2}{*}{$\alpha=90^{\circ}$} & 1 & 5.15051 & 5.14912 & $0.03 \%$ \\
& 2 & 5.27945 & 5.27765 & $0.03 \%$ \\
& 3 & 9.42541 & 9.40889 & $0.18 \%$ \\
& 4 & 12.4088 & 12.37671 & $0.26 \%$ \\
$\alpha=150^{\circ}$ & 5 & 14.3156 & 14.25922 & $0.40 \%$ \\
\hline & 1 & 5.15063 & 5.14912 & $0.03 \%$ \\
& 2 & 5.27544 & 5.27331 & $0.04 \%$ \\
& 4 & 9.41916 & 9.40088 & $0.19 \%$ \\
& 4 & 12.3053 & 12.27255 & $0.27 \%$ \\
& 5 & 14.162 & 14.10833 & $0.38 \%$ \\
\hline
\end{tabular}

TABLE 6: Dimensionless free vibration frequencies of the cantilevered twofold laminated plate with the lamination scheme $\left(-45^{\circ} / 45^{\circ} /-45^{\circ} / 45^{\circ} /-45^{\circ} \ldots\right)_{10}$.

\begin{tabular}{lcccc}
\hline Crank angle & Modes & $\begin{array}{c}\text { Present } \\
\text { results }\end{array}$ & $\begin{array}{c}\text { ANSYs } \\
\text { results }\end{array}$ & $\begin{array}{c}\text { Relative } \\
\text { errors }\end{array}$ \\
\hline \multirow{2}{*}{$\alpha=90^{\circ}$} & 1 & 5.55864 & 5.53036 & $0.51 \%$ \\
& 2 & 6.01129 & 5.98305 & $0.47 \%$ \\
& 3 & 13.3613 & 13.2764 & $0.64 \%$ \\
$\alpha=150^{\circ}$ & 4 & 16.8974 & 16.755 & $0.85 \%$ \\
& 5 & 18.1847 & 18.02859 & $0.87 \%$ \\
\hline & 1 & 5.55885 & 5.51233 & $0.84 \%$ \\
& 3 & 5.9971 & 5.94399 & $0.89 \%$ \\
& 4 & 13.4186 & 13.21197 & $1.56 \%$ \\
& 5 & 16.8014 & 16.59041 & $1.27 \%$ \\
\hline
\end{tabular}

TABLE 7: Dimensionless free vibration frequencies of the cantilevered tub structure with the lamination scheme $\left(0^{\circ} / 90^{\circ} / 90^{\circ} / 0^{\circ}\right)$.

\begin{tabular}{lccc}
\hline Modes & Present results & ANSYS results & Relative errors \\
\hline 1 & 9.14727 & 9.126463 & $0.23 \%$ \\
2 & 9.14957 & 9.126797 & $0.25 \%$ \\
3 & 14.1263 & 14.06026 & $0.47 \%$ \\
4 & 23.6554 & 23.53825 & $0.50 \%$ \\
5 & 31.4647 & 31.43285 & $0.10 \%$ \\
\hline
\end{tabular}

TABLE 8: Dimensionless free vibration frequencies of the cantilevered tub structure with the lamination scheme $\left(-45^{\circ} / 45^{\circ} /-45^{\circ} /\right.$ $\left.45^{\circ} /-45^{\circ} \ldots\right)_{10}$.

\begin{tabular}{lccc}
\hline Modes & Present results & ANSYS results & Relative errors \\
\hline 1 & 12.6681 & 12.56399 & $0.83 \%$ \\
2 & 12.7663 & 12.56399 & $1.61 \%$ \\
3 & 18.6702 & 18.49329 & $0.96 \%$ \\
4 & 31.407 & 31.05495 & $1.13 \%$ \\
5 & 33.1907 & 32.96984 & $0.67 \%$ \\
\hline
\end{tabular}

laminates 2 and 3 to be $\left(45^{\circ} /-45^{\circ} /-45^{\circ} / 45^{\circ}\right)$, as is demonstrated in Figure 21(b); and Case 3: laminate 1 is taken to be $\left(90^{\circ} / 0^{\circ} / 0^{\circ} / 90^{\circ}\right)$ and laminates 2 and 3 to be $\left(0^{\circ} / 90^{\circ} / 90^{\circ} / 0^{\circ}\right)$, as is shown in Figure 21(c).

The dimensionless frequencies of the first five vibration modes of the structures are computed by both the proposed method and ANSYS and listed in Tables 9, 10, and 11, and the first five mode shapes are shown in Figures 22, 23, and 24. In ANSYS, 4800 elements are used to discretise the structure. The agreement of the two sets of results is good. 
TABLE 9: Dimensionless free vibration frequencies of the laminated shell (Figure 21(a)).

\begin{tabular}{lccc}
\hline Modes & Present results & ANSYS results & Relative errors \\
\hline 1 & 8.10352 & 8.01745 & $1.1 \%$ \\
2 & 8.10352 & 8.01745 & $1.1 \%$ \\
3 & 10.01294 & 9.86091 & $1.5 \%$ \\
4 & 13.70969 & 13.49473 & $1.6 \%$ \\
5 & 15.17441 & 14.93191 & $1.6 \%$ \\
\hline
\end{tabular}

TABLE 10: Dimensionless free vibration frequencies of the laminated shell (Figure 21(b)).

\begin{tabular}{lccc}
\hline Modes & Present results & ANSYS results & Relative errors \\
\hline 1 & 9.18846 & 9.08674 & $1.1 \%$ \\
2 & 9.18846 & 9.08674 & $1.1 \%$ \\
3 & 9.65333 & 9.58148 & $0.7 \%$ \\
4 & 13.41558 & 13.23601 & $1.4 \%$ \\
5 & 14.99186 & 14.81606 & $1.2 \%$ \\
\hline
\end{tabular}

TABLE 11: Dimensionless free vibration frequencies of the laminated shell (Figure 21(c)).

\begin{tabular}{lccc}
\hline Modes & Present results & ANSYS results & Relative errors \\
\hline 1 & 7.09973 & 7.07069 & $0.4 \%$ \\
2 & 7.09973 & 7.07069 & $0.4 \%$ \\
3 & 9.75645 & 9.71035 & $0.5 \%$ \\
4 & 15.16616 & 15.11418 & $0.3 \%$ \\
5 & 18.02388 & 17.94379 & $0.4 \%$ \\
\hline
\end{tabular}

\section{Conclusions}

An element-free Galerkin method that is based on the FSDT is proposed for the free vibration analysis of folded symmetrically laminated plate structures. A folded laminated plate is considered to be a composite structure of flat symmetrical laminates. The global stiffness and mass matrices of the folded plate are formed by superposing the stiffness and mass matrices of the laminates that are derived with the meshfree method. In order to ensure the success of the superposition, a treatment initially developed for the enforcement of essential boundary conditions is extended to modify the stiffness and mass matrices before the superposition, which has overcome the difficulties that the EFG handles displacement compatibility and improved the applicability of EFG to composite structures. The proposed method does not rely on meshes; therefore, mesh disorder due to the large deformation of problem domain is avoided. The convergence and accuracy of the proposed method are demonstrated by a comparison of the solutions of several examples with those that are given by ANSYS. Good agreement between the two sets of results is observed. The proposed method used a relatively small number of nodes to obtain the calculated results close to the

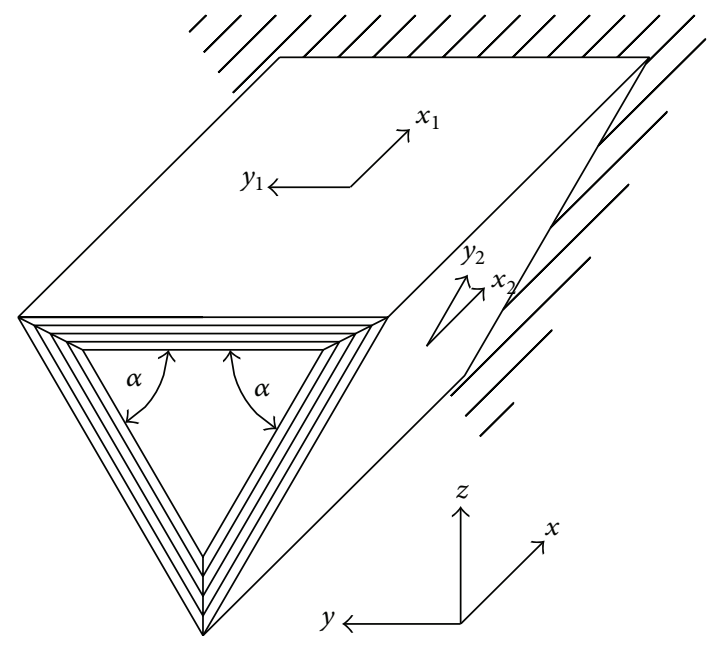

FIGURE 18: A tub structure with three folds.

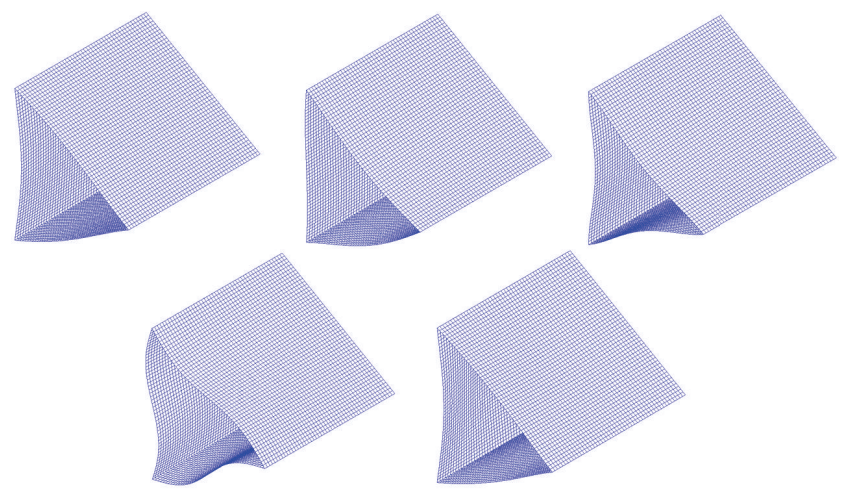

FIGURE 19: First five vibration mode shapes of the tub structure.

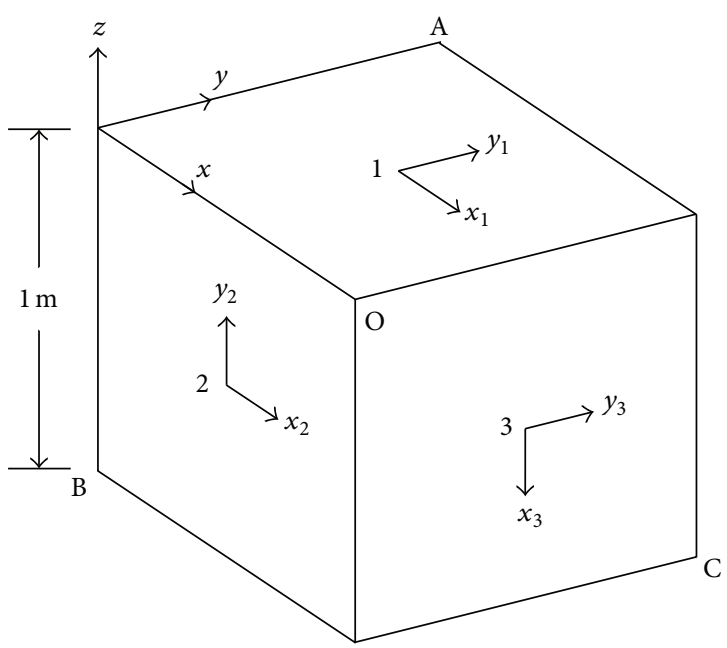

Figure 20: A laminated shell structure.

solutions given by ANSYS with a large number of nodes, and the linear analysis by the proposed meshless method in the paper can be the basis for future nonlinear analysis. The treatment introduced with the proposed method has provided a clue for EFG to be applied to composite structures. 


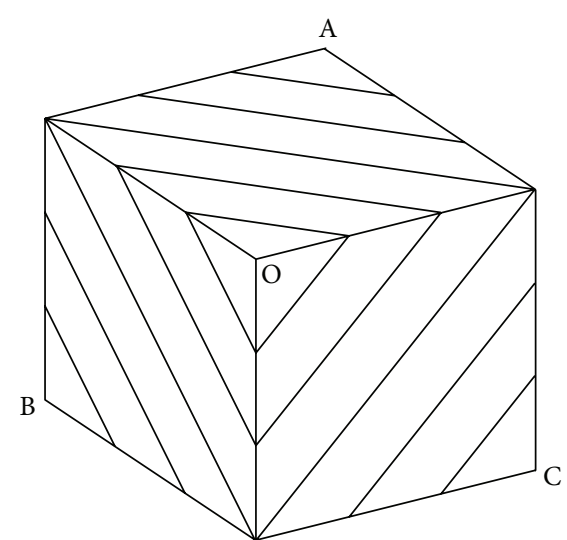

(a)

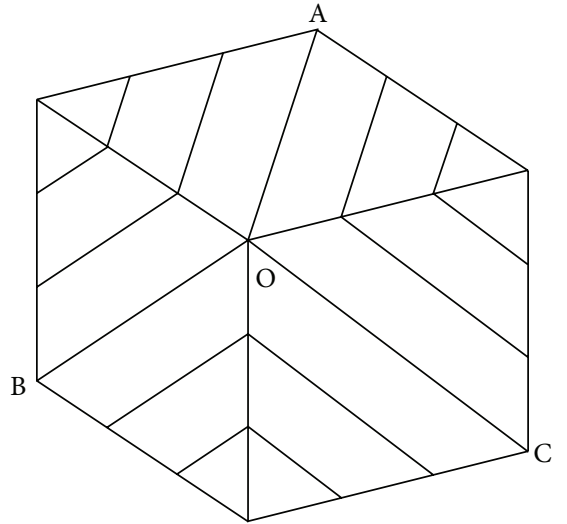

(b)

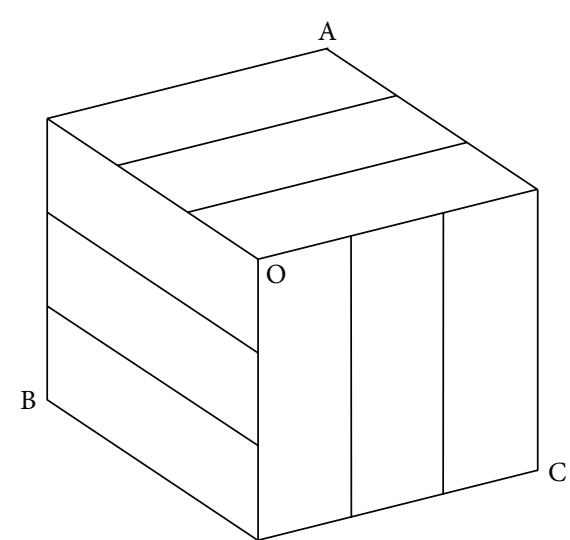

(c)

FIGURE 21: Lamination schemes of the laminated shell.

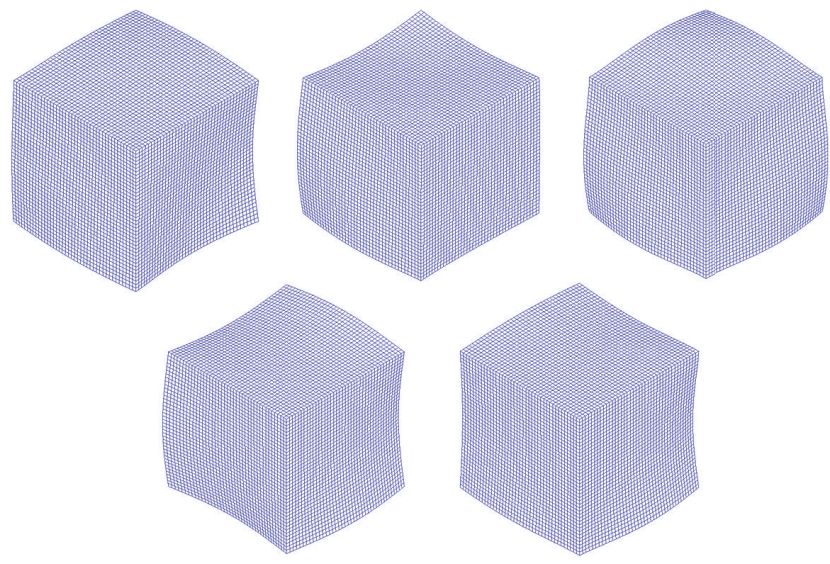

Figure 22: First five vibration mode shapes of the laminated shell (Case 1).

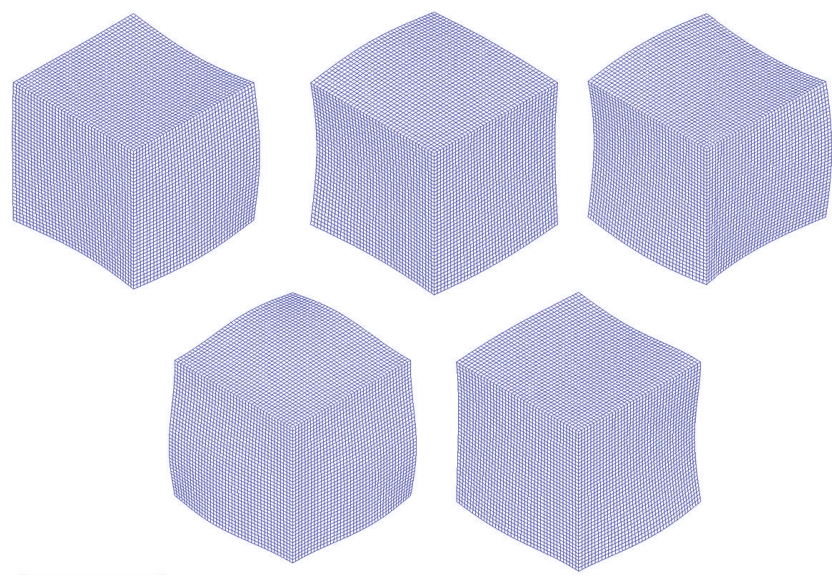

Figure 23: First five vibration mode shapes of the laminated shell (Case 2).

\section{Conflict of Interests}

The author declares that there is no conflict of interests regarding the publication of this paper.

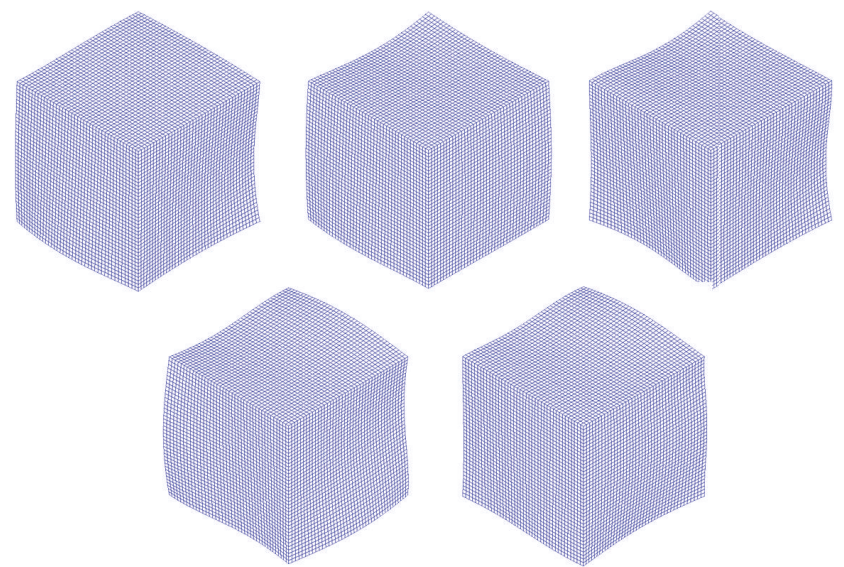

FIGURE 24: First five vibration mode shapes of the laminated shell (Case 3).

\section{Acknowledgments}

The work that is described in this paper has been supported by the grants awarded by the National Natural Science Foundation of China (Projects nos. 11102044, 51168003, and 11562001), the Systematic Project of Guangxi Key Laboratory of Disaster Prevention and Structural Safety (Project no. 2012ZDX07), and Key Project of Guangxi Science and Technology Lab Center (Fund no. LGZX201101).

\section{References}

[1] Task Committee, "Phase I report on folded plate construction. Report of the Task Committee on folded plate construction. Committee on Masonry and Reinforced Concrete of the Structural Division," Journal of Structural Division, vol. 89, pp. 365406, 1963.

[2] I. Gaafar, "Hipped plate analysis considering joint displacement," Transaction of ASCE, vol. 119, pp. 743-784, 1954.

[3] D. Yitzhaki, The Design of Prismatic and Cylindrical Shell Roofs, Haifa Science, Haifa, Israel, 1958.

[4] D. Yitzhaki and M. Reiss, "Analysis of folded plates," ASCE Journal of the Structural Division, vol. 88, pp. 107-142, 1962. 
[5] C. S. Whitney, B. G. Anderson, and H. Birnbaum, "Reinforced concrete folded plate construction," ASCE Journal of the Structural Division, vol. 85, pp. 15-43, 1959.

[6] J. E. Goldberg and H. L. Leve, "Theory of prismatic folded plate structures," International Association for Bridge and Structural Engineering, vol. 17, pp. 59-86, 1957.

[7] A. G. Niyogi, M. K. Laha, and P. K. Sinha, "Finite element vibration analysis of laminated composite folded plate structures," Shock and Vibration, vol. 6, no. 5, pp. 273-283, 1999.

[8] P. Bar-Yoseph and I. Hersckovitz, "Analysis of folded plate structures," Thin-Walled Structures, vol. 7, no. 2, pp. 139-158, 1989.

[9] J. N. Bandyopadhyay and P. K. Laad, "Comparative analysis of folded plate structures," Computers \& Structures, vol. 36, no. 2, pp. 291-296, 1990.

[10] Y. Lai, Z. Wu, Y. Zhu, and A. Sun, "Geometrical non-linear analysis of a simply-supported cross V-shaped folded plate roof," Thin-Walled Structures, vol. 37, no. 3, pp. 259-275, 2000.

[11] Y. K. Cheung, "Folded plate structures by finite strip method," Journal of the Structural Division, ASCE, vol. 95, pp. 2963-2979, 1969.

[12] B. W. Golley and W. A. Grice, "Prismatic folded plate analysis using finite strip-elements," Computer Methods in Applied Mechanics and Engineering, vol. 76, no. 2, pp. 101-118, 1989.

[13] A. L. Eterovic and L. A. Godoy, "An exact strip method for folded plate structures," Computers and Structures, vol. 32, no. 2, pp. 263-276, 1989.

[14] M. Ohga, T. Shigematsu, and S. Kohigashi, "Analysis of folded plate structures by a combined boundary element-transfer matrix method," Computers and Structures, vol. 41, no. 4, pp. 739-744, 1991.

[15] W. H. Liu and C. C. Huang, "Vibration analysis of folded plates," Journal of Sound and Vibration, vol. 157, no. 1, pp. 123-137, 1992.

[16] B. Perry, P. Bar-Yoseph, and G. Rosenhouse, "Rectangular hybrid shell element for analysing folded plate structures," Computers and Structures, vol. 44, no. 1-2, pp. 177-185, 1992.

[17] M. Duan and Y. Miyamoto, "Effective hybrid/mixed finite elements for folded-plate structures," Journal of Engineering Mechanics, vol. 128, no. 2, pp. 202-208, 2002.

[18] T. Belytschko, Y. Y. Lu, and L. Gu, "Element-free Galerkin methods," International Journal for Numerical Methods in Engineering, vol. 37, no. 2, pp. 229-256, 1994.

[19] J.-S. Chen, C. Pan, C.-T. Wu, and W. K. Liu, "Reproducing kernel particle methods for large deformation analysis of nonlinear structures," Computer Methods in Applied Mechanics and Engineering, vol. 139, no. 1-4, pp. 195-227, 1996.

[20] L. X. Peng, S. Kitipornchai, and K. M. Liew, "Bending analysis of folded plates by the FSDT meshless method," Thin-Walled Structures, vol. 44, no. 11, pp. 1138-1160, 2006.

[21] L. X. Peng, S. Kitipornchai, and K. M. Liew, "Analysis of rectangular stiffened plates under uniform lateral load based on FSDT and element-free Galerkin method," International Journal of Mechanical Sciences, vol. 47, no. 2, pp. 251-276, 2005.

[22] L. X. Peng, S. Kitipornchai, and K. M. Liew, "Free vibration analysis of folded plate structures by the FSDT mesh-free method," Computational Mechanics, vol. 39, no. 6, pp. 799-814, 2007.

[23] T. Q. Bui, M. N. Nguyen, and C. Zhang, "An efficient meshfree method for vibration analysis of laminated composite plates," Computational Mechanics, vol. 48, no. 2, pp. 175-193, 2011.
[24] T. Q. Bui and M. N. Nguyen, "Meshfree Galerkin Kriging model for bending and buckling analysis of simply supported laminated composite plates," International Journal of Computational Methods, vol. 10, no. 3, Article ID 1350011, 2013.

[25] M. Somireddy and A. Rajagopal, "Meshless natural neighbor Galerkin method for the bending and vibration analysis of composite plates," Composite Structures, vol. 111, no. 1, pp. 138-146, 2014.

[26] S.-Y. Lee, S.-C. Wooh, and S.-S. Yhim, "Dynamic behavior of folded composite plates analyzed by the third order plate theory," International Journal of Solids and Structures, vol. 41, no. 7, pp. 1879-1892, 2004.

[27] J. N. Reddy, Theory and Analysis of Elastic Plates, Taylor \& Francis, London, UK, 1999.

[28] J. N. Reddy and A. Miravete, Practical Analysis of Composite Laminates, CRC Press, Boca Raton, Fla, USA, 1995.

[29] SHELL99, Element Reference, ANSYS Documentation. 


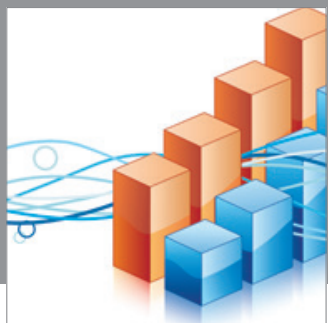

Advances in

Operations Research

mansans

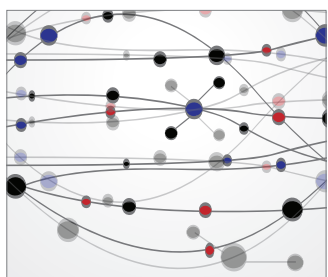

The Scientific World Journal
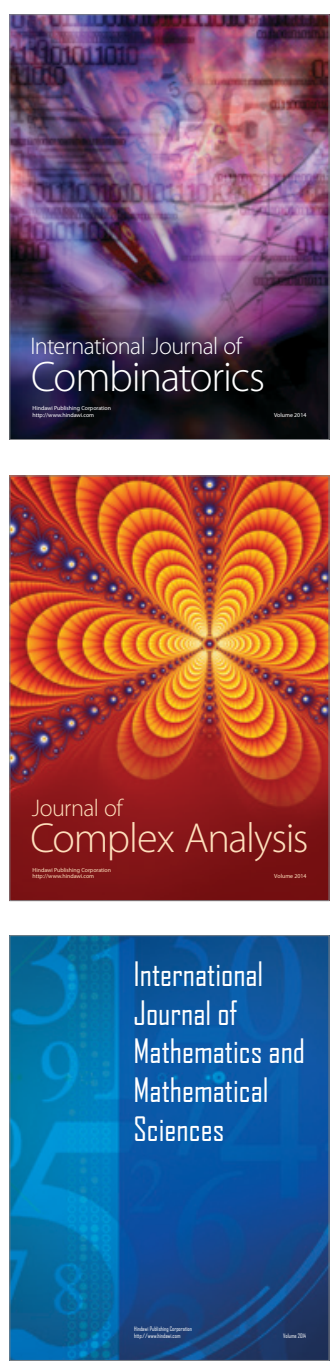
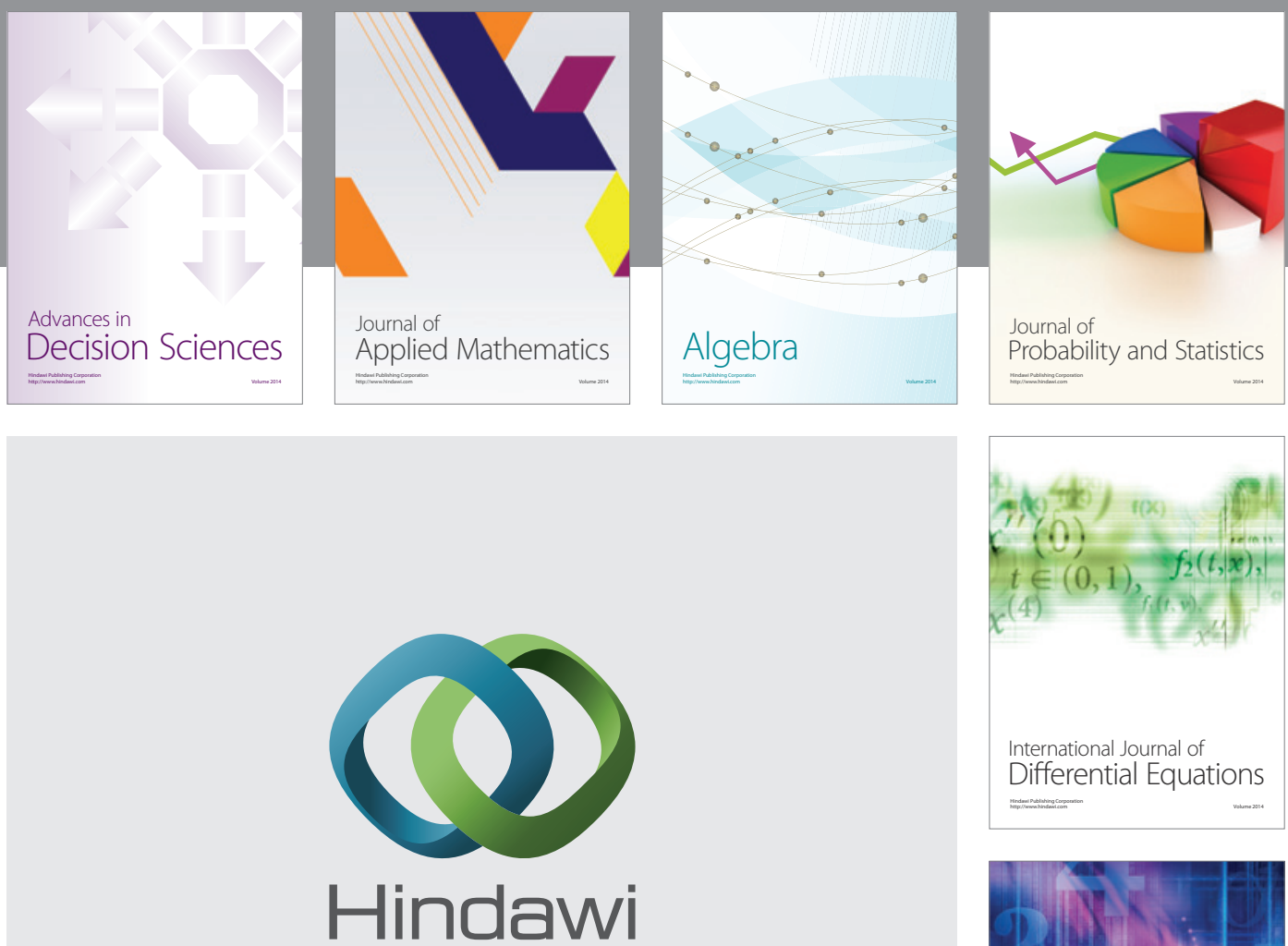

Submit your manuscripts at http://www.hindawi.com
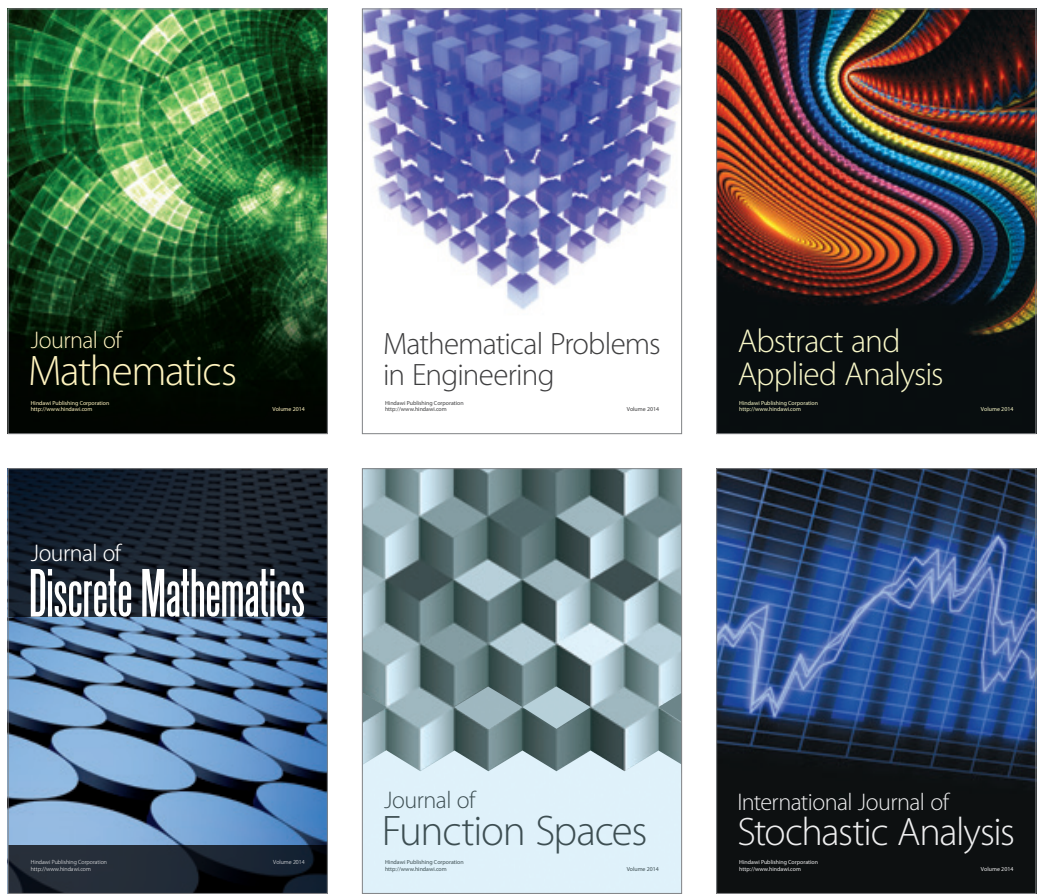

Journal of

Function Spaces

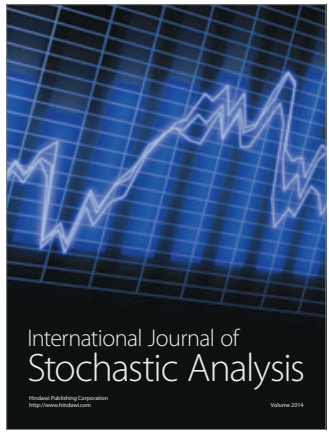

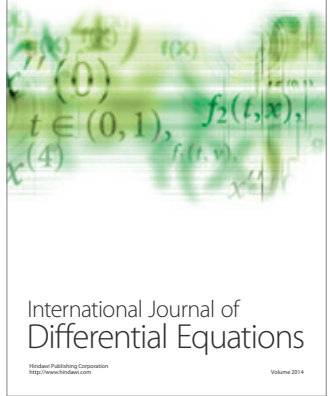
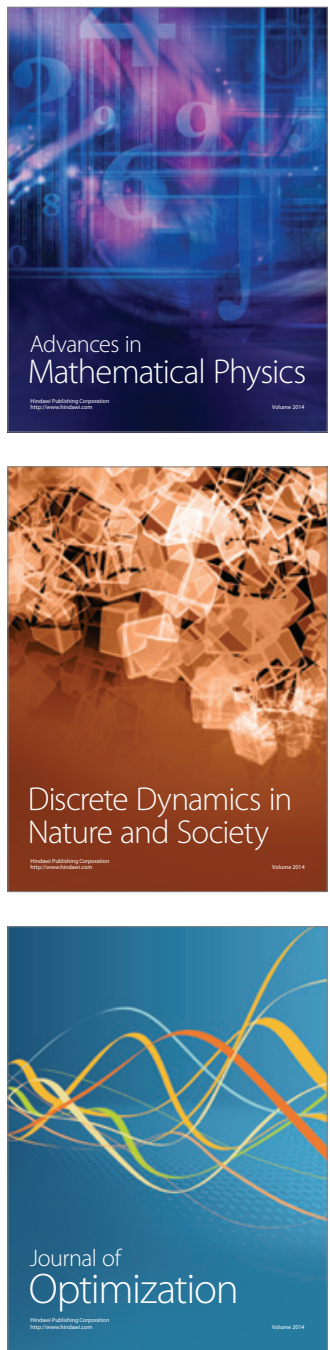